Article

\title{
Antioxidant and reduced skin ageing effects of a polyphenol-enriched dietary supplement in response to air pollution: a randomized, double-blind, placebo-controlled study
}

\author{
Vincenzo Nobile ${ }^{2}$, Irene Schiano ${ }^{2}$, Ana Peral 1, Silvana Giardina ${ }^{2}$, Eleonora Spartà ${ }^{2}$ and Nuria \\ Caturla ${ }^{1, *}$ \\ 1 Monteleoder SA, MiguelServet 16, 03203 Elche, Alicante, Spain; nuria caturla@monteloeder.com (N.C); \\ anaperal@monteloeder.com (A.P) \\ 2 Complife Italia Srl, Via Monsignor Angelini21, San Martino Siccomario, 27028 Pavia, Italy: \\ vincenzo.nobile@complifegroup.com (V.N); irene.schiano@complife group.com (I.S); \\ silvana.giardina@complife group.com (S.G); eleonora.sparta@complifegroup.com (E.S) \\ * Correspondence: nuriacaturla@monteloeder.com
}

\begin{abstract}
Repeated air pollution exposure is one of the major threats to skin health. Air pollution causes skin damage and accelerates skin ageing mainly through oxidative stress mechanisms. Since it is difficult to minimize skin exposure from air pollutants, especially in urban areas, strategies to protect the skin are needed. On the other hand, plant phenolic compounds have been found to be effective in attenuating cellular oxidative stress and inflammation induced by different air pollutants. Therefore, we conducted a 12-week randomized, placebo-controlled, doubleblind study to assess the efficacy of a polyphenol-enriched dietary supplement (comprised of olive leaf, lemon verbena, rosemary and Sophora japonica extracts) in reducing pollution-induced oxidative stress and in improving different skin parameters related to skin ageing of Caucasian and Asian volunteers living in a polluted urban European area (Milan). One hundred healthy women were recruited and randomized in the placebo or in the test dietary supplement treatmentarms. To assess the efficacy of the dietary supplement, the total antioxidant capacity on saliva (FRAP) was determined, as well as the oxidative damage on skin (lipoperoxides content), the skin moisture (corneometry), the trans-epidermal water loss (Tew ameter), the skin radiance and the skin colour, (spectrophotometry), the skin elasticity (cutometry), the skin sebum content (sebumeter), and the skin roughness (image analysis). As a result, both inter-group and intra-group analysis proved that the dietary supplement improved all clinical and biochemical monitored parameters, in both Caucasian and Asian individuals. In conclusion, the results of the study indicate a reduced oxidative stress-induced skin damage in both Asian and Caucasian women living in a polluted urban area.
\end{abstract}

Keywords: air pollution; skin; nutraceutical; natural compound, polyphenols, antioxidant, skin barrier, anti-ageing, pigmentation, hydration, clinical trial

\section{Introduction}

Air pollution has become a major problem in recent decades and is view ed as the w orld's largest environmental health risk factor, responsible for millions of deaths globally each year. A new WHO air quality model confirms that $92 \%$ of the world's population lives in cities where air quality levels exceed healthy limits [1].

The sources of pollution vary from cigarettes, natural sources (such as windblown dust, sea-salt spray or volcanic eruptions) to large volumes of emission from transport and industrial activities. The pollutants of major concern regarding public health a re fine particulate matter (PM), defined by a diameter $\leq 0.1 \mu \mathrm{m}$ (UFP), $\leq 2.5 \mu \mathrm{m}$ (PM2.5) or $\leq 10 \mu \mathrm{m}$ (PM10); gases, such as nitrogen dioxide $\left(\mathrm{NO}_{2}\right)$, 
carbon monoxide (CO), volatile organic compounds (VOCs) or ground-level ozone $\left(\mathrm{O}_{3}\right)$; and toxic chemicals, for instance, polycyclic aromatic hydrocarbons (PAH) and dioxins.

Although it is reasonable to assume that the skin is one of the first organs to be affected by air pollution, our knowledge regarding the harmful effects of air pollution on skin physiology remains limited. It has been recently shown that air pollution, mainly particulate matter, can penetrate the skin barrier and alter its redox status [2,3]. PM induces oxidative stress, increases ROS production and secretion of pro-inflammatory cytokines, resulting in lipid peroxidation and DNA damage. This further increases matrix metalloproteinases, (MMPs)-1, -2, and -9, which degrade collagen [4]. Aside from solar radiation (UVR), pollution has been recognized as one of the driving factors that accelerates skin ageing, such as pigment spots on face, nasolabial folds, and wrinkles [5]. Furthermore, recent studies suggest that the effects of UV radiation and air pollution are not independent of each other, suggesting that facial lentigines are the consequence of an interplay of UVR and traffic air related pollutants [6].

Several mechanisms through which air pollutants cause skin damage and ageing have been proposed. Specifically, the current evidence indicates four potential mechanisms: (i) increased skin oxidative stress, (ii) promotion of a proinflammatory environment in the skin and disruption of the skin barrier, (iii) activation of the aryl hydrocarbon receptor (AhR), and (iv) alteration of the skin microbiome [7].

The damaging effects of air pollution may lead to skin disorders, including sensitive skin, skin dryness, accelerated skin ageing and abnormal pigmentation, among others [8-11]. Air pollutants are also involved in the onset of atopic dermatitis, eczema, skin rashes, and skin cancers [12,13]. Studies have also shown that those living in highly polluted areas have significantly w orse skin hydration and reduced skin barrier function than subjects living in the cleaner suburbs despite making better lifestyle choices. Therefore, efficient protection of the skin against the air pollution exposure is very important not only for cosmetic reasons.

Topical skincare products are eligible candidates to protect the skin from air pollution. They act upon two major pathways : limiting pollution contact with the skin due to their intrinsic film-forming properties, and by incorporating ingredients $w$ ith antioxidative properties to minimize the damaging effect of pollutants [14]. However, topical solutions do not seem to be sufficient for effective protection against pollution. This is because cosmetics can only protect the most external layers of the skin, while it is known that internal structures of the skin can also be affected. Ultrafine particles (UFP) and PAHs may accumulate in the hypodermis, dermis, and bottom of the hair follicle, which are highly vascularized, and can even reach the deep epidermis [15]. Moreover, certain pollutants can penetrate the skin via indirect systemic distribution of inhaled or ingested pollution through the blood [15-17]. It is for these reasons that the shielding efficacy of skincare products should be complemented with a dietary approach in a more sophisticated skin-protecting strategy. The dietary approach, in fact, could be an adequate candidate to replenish the skin with nutrients able to increase the repairing mechanisms from the effect of chronic air pollution exposure. Several clinical trials have shown that supplementation with natural compounds such as vitamins, minerals, plant poly phenols, carotenoids, collagen peptides, etc. has shown to have anti-ageing and photoprotective effects [1820]. Moreover, there is substantial evidence that including antioxidants in the diet, in the form of fresh foods or through food supplements, may play a role in modulating the acute effects of air pollutants in lung function and cardiovascular system [21,22]. 
Extracts and phenolic compounds derived from many plants, such as blueberry, green tea, grape, pomegranate, different marine algae, have been proven to be effective in attenuated the cellular oxidative stress and the inflammation induced by different air pollutants [23-28]. Published studies have shown that extracts from Lippia citriodora leaf, Olea europaea leaf, Sophora japonica, and Rosmarinus officials, as w ell as its main bioactive phenolic compounds, are effective antioxidants with the ability to counteract different environmentally-induced skin damage[29-39]. Also, a preliminary study of a blend of these 4 herbal extracts standardized in verbascoside, oleuropein, hydroxytorosol, quercetin and rosemary diterpenes (carnosic acid and carnosol) demonstrated the photo-urban pollution protective efficacy in keratinocytes cell model and in living human skin explants. This commercially and patented ingredient (ZeroPollution ${ }^{\circledR}$, Monteloeder S.L., Spain) showed, among other effects, significantly antioxidant and anti-inflammatory properties in skin explants exposed to pollutants $[40,41]$.

Based on all the above findings, in the current study we investigated in vivo the efficacy of the test product against the detrimental effects of air pollution on the skin. To this end, a double-blind, placebo-controlled study was performed to evaluate the efficacy of this four-extract blend in improving the skin condition of Caucasian and Asian females living in a homogenous urbanized, high pollution area and that spend at least 2 hours daily outdoors. Milan was chosen as it is one of the most polluted cities in Europe [42].

When assessing active ingredients for their performance against exposure to pollution, safety considerations are of primary importance and exposing humans to pollutants can be pose ethical consideration concerning health hazards. In this sense, testing the product in real-life conditions in volunteers selected based on their living conditions and lifestyle, e.g., people who spend a large amount of time in highly polluted areas, are generally recruited to study the antipollution properties of cosmetic ingredients $[24,43,44]$.

Here, we demonstrate that the intake of the polyphenolic-enriched blend (Rosmarinus officinalis, Olea Europaea, Lippia citriodora and Sophora japonica) for 12 weeks significantly improves systemic and skin oxidative status, strengthens the skin barrier, improves skin moisturization, regulates the sebum secretion and provides anti-ageing skin benefits, versus the placebo group.

\section{Materials and Methods}

\subsection{Study design and Ethics statement}

A monocentric, stratified (50\% Asian and 50\% Caucasian subjects), randomized, double-blind, placebo-controlled, parallel-group study w as conducted in Italy during the winter period.

The study took place at Complife Group facilities in Milan (MI) in accordance with the Declaration of Helsinki (Ethical Principles for Medical Research Involving Human Subjects). Complife Group is an independent testing laboratory for in vitro and in vivo safety and efficacy assessment of cosmetics, food supplements and medical devices. The study protocol and the informed consent form were approved by the "Independent Ethical Committee for NonPharmacological Clinical trials" (ref. 2018/11). Subjects were randomly assigned to the test dietary supplement and placebo group in a 1:1 ratio allocation rate. All subjects provided written informed consent before initiation of any study-related procedures. No changes to treatment regimen or methods werenecessary after the study initiation.

\subsection{Subjects}


Inclusion criteria included adults, Asian and Caucasian (1:1 ratio) female subjects, aged betw een 35 and 65 years old, with normal or sensitive skin (1:1 ratio), dark spots on the face, that spend at least 2 hours outdoors every day in an urbanized area.Subjects were of general good health without any alimentary and/or eating disorders (i.e. bulimia, psychogenic eating disorders, etc.). Exclusion criteria included pregnancy or intention to become pregnant, lactation, food intolerances/allergy, pharmacological treatments and/or food supplement intake known to interfere with the test product or influencing metabolism, participation in another dietary supplement study, unwillingness or inability to comply with the requirements of the study protocol. The study further excluded subjects using products known to interfere with product efficacy and/or with the study outcomes and subjects not willing to refrain from sun exposure if not properly protected. Throughout the study period, subjects were asked to only use the supplied face cream and soap.

\subsection{Intervention}

The test item was a patented commercially available food supplement ingredient (ZeroPollution ${ }^{\circledR}$, supplied by Monteloeder S.L., Miguel Servet 16, Elche, Alicante, Spain) containing Rosmarinus officinalis leaf extract, Olea Europaea leaf extract, Lippia citriodora leaf extract and Sophora japonica extract (WO/2019/211501). In total, w/w, this blend comprises a minimum content of: diterpenes (sum of carnosic acid and carnosol) 4.5\%; oleuropein 4.5\%; hydroxytyrosol 1.5\%; verbascoside $6.5 \%$; and quercetin 3.5\%. Each capsule contained $250 \mathrm{mg}$ active ingredient and $120 \mathrm{mg}$ microcrystalline cellulose. The placebo product contained $250 \mathrm{mg}$ maltodextrin and $120 \mathrm{mg}$ microcrystalline cellulose. To enhance study blindness, both the placebo and active capsules colour was adjusted with FD\&C Blue 2 and titanium dioxide. After the initial visit, subjects started taking 1 capsule of the dietary supplement or the placebo product every day for $12 \mathrm{w}$ eeks. The product intake was 30 minutes before breakfast. To standardize the daily cosmetic routine, subjects were supplied with a neutral day/night cream and a cleansing lotion.

\subsection{Primary and secondary outcomes}

The primary endpoints concerning the efficacy in protecting the skin against environmental pollutants were the measurement of the total antioxidant capacity in the saliva and in the skin. Skin moisturization, sebum content, elasticity, colour, radiance and roughness analysis w ere measured as secondary endpoints. A self-assessment efficacy evaluation questionnaire w as also performed after 1 month and at the end of the study to evaluate the perceived efficacy by the subjects. The study flow and the schedule of assessments chart are reported in Figure 1.

\subsubsection{Measurement of skin lipoperoxides}

Basal skin lipoperodixes (LPO) were measured in the $10^{\text {th }}$ skin layer obtained using the skin stripping technique. Skin stripping was performed in the back using Corneofix ${ }^{\circledR}$ foils (Courage+Khazaka Electronic, Köln, Germany) under standard pressure conditions $\left(225 \mathrm{~g} / \mathrm{cm}^{2}\right)$. The first stripping was discarded while strip no. 10 was collected and stored at $-80^{\circ} \mathrm{C}$ until further analysis. Malondialdehyde (MDA) was measured according to the assay described by Erdelmeier et al. in 1998 [18, 45] with minor modification [18], as follows: 1) skin strippings were layered in 12 multiwell plates containing $500 \mu \mathrm{l}$ of a $0.5 \mathrm{mM} \mathrm{CuSO}_{4}$ aqueous solution, 2) multiwell plates were incubated at $37^{\circ} \mathrm{C}$, using a microplate incubator/shaker under continuous agitation for $1 \mathrm{~h}, 3$ ) after incubation $1.3 \mathrm{ml} \mathrm{R} 1$ solution $(2.13 \mathrm{mg} \mathrm{N}$-methyl-2-phenylindole/ml acetonitrile) and $0.3 \mathrm{ml} 37 \% \mathrm{HCl}$ w as added and samples were further incubated at $45^{\circ} \mathrm{C}$ for $60 \mathrm{~min}$ under continuous agitation, 4) the reaction was stopped in ice for $10 \mathrm{~min}$ followed by $10 \mathrm{~min}$ at room temperature, 5) $1 \mathrm{ml}$ of solution was centrifuged at $13.000 \mathrm{rpm}$ per $10 \mathrm{~min}$, and 6) absorbance was read at $586 \mathrm{~nm}$ using a multi well plates reader (programmableMPT reader model DV 990BV6; Gio DeVita \& C, Rome, Italy). 


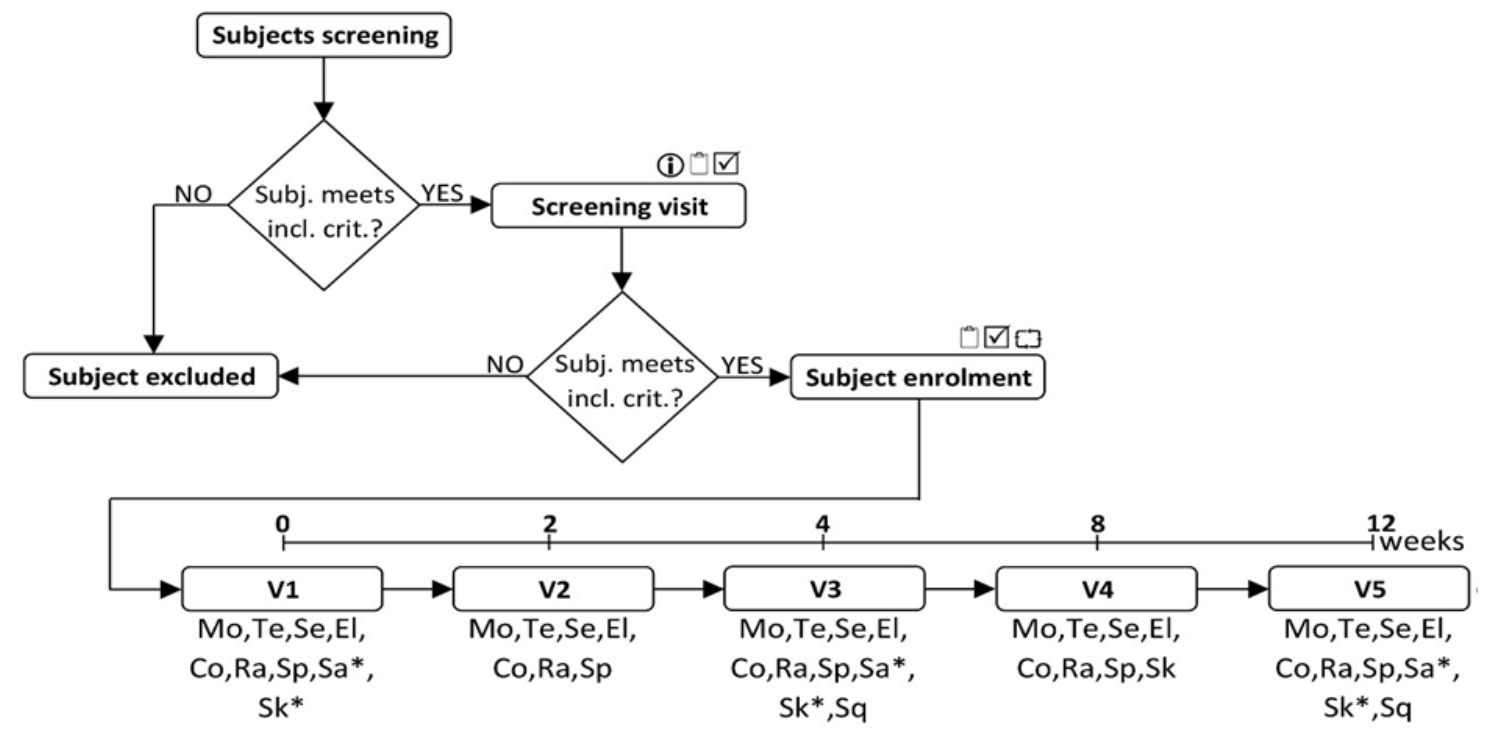

Figure 1. Study flow and sche dule of assessments chart. Subjects we re first screened in the volunteer's da tabase (keywords: Sex "female", Age "35-65", Ethnicity "Asian and Cauca sian" Skin type "normal and sensitive", Testing preferences: 'food supplements'). Eligible participants we re then screened by a board-certified dermatologist. During the screening visit, a physical examination was carried out in order to assess the skin conditions. Subjects meeting the inclusion criteria were then enrolled and randomised. Legend: (i) informed consent; $\square$ physical examination; $\nabla$ eligibility check; $\square$ randomisation; daily journal; Mo skin moisturization; Te Transepidermal water loss (TEWL); Se Skin sebum content; ElSkin elasticity (R0 and R2 pa ra meters); Co Skin colour (pigmentation); Ra Skin radiance; Ta ;Sp Skin profilome try; Sa Saliva samples collection; Sk Skin stripping; Sq Self-a ssessment questionnaire; *After collection Sa and Sk sample s were stored to $-80^{\circ} \mathrm{C}$ for further analysis.

\subsubsection{Measurement of total antioxidant capacity of saliva}

The total antioxidant capacity of saliva (TAS) was measured using the Ferric Reducing Antioxidant Power technique (FRAP) described by Benzie at al. in 1996 [46]. FRAP is based on the reduction of a ferric-tripyridyltriazine (FeIII-TPTZ) complex to the ferrous (FeII) form at a low $\mathrm{pH}$. The ferric to ferrous reduction causes a blue-coloured ferrous-tripyridyltriazine complex to form. Briefly, $30 \mu \mathrm{L}$ of distilled water, $160 \mu \mathrm{L}$ of w orking FRAP reagent $(25 \mathrm{~mL}$ acetate buffer, $2.5 \mathrm{~mL}$ TPTZ solution and $2.5 \mathrm{~mL} \mathrm{FeCl3} 6 \mathrm{H} 2 \mathrm{O}$ solution) and $10 \mu \mathrm{L}$ saliva sample were added in a 96 multiwell plate. The samples were then incubated at $37^{\circ} \mathrm{C}$ using a microplate incubator/shaker with 30 minutes of continuous agitation. Absorbance was read at $595 \mathrm{~nm}$.

\subsubsection{Measurement of skin moisturization}

Skin moisturization was measured using a Corneometer ${ }^{\circledR}$ CM 825 (Courage+Khazaka Electronic, Köln, Germany). Corneometer ${ }^{\circledR}$ probe measures the capacitance of the stratum corneum using an electric scatter field penetrating the first layers of the stratum corneum $(10-20 \mu \mathrm{m})$. The capacitance variation of the probe capacitor due to skin surface hydration was measured and skin moisturization was reported in arbitrary units (corneometric units). The measurement was taken in 5 different points of the right cheek. The selected measurement points delineate the vertices and the centre of a quadrangle virtually drawn across the cheek. An increase in the Corneometer value is indicative of a skin-moisturizing effect.

\subsubsection{Measurement of w rinkle depth and skin roughness}

Wrinkle depth and skin roughness (Ra parameter) were measured using a three-dimensional (3D) microtopography imaging system (PRIMOS 3D lite, GFMesstechnik GmbH, Teltow, Germany). The imaging system projects structured light on a specific surface of the skin w ith a digital micromirror device (DMD, Texas Instruments, Irving, TX, USA) and records the image with a CCD camera. Skin surface microtopography is then reconstructed using temporal phase shift algorithms to 
generate 3-D images. The imaging system has an overlap feature which enables precise matching of photos taken at different visits. In order to improve image overlap, the subjects' position was regulated using a stereotactic device (Canfield Scientific, Inc., Fairfield, NJ, USA). Wrinkle depth and skin roughness were measured in the periocular area ('crow's feet w rinkles') using the appropriate software routine. Ra parameter is related to skin smoothness and a decrease of Ra can be expressed in absolute values as an increase in skin smoothness.

\subsubsection{Measurement of Transepidermal Water Loss (TEWL)}

Transepidermal water loss (TEWL, perspiratio insensibilis) was measured using a Tew ameter ${ }^{\circledR} \mathrm{TM}$ 300 (Courage+Khazaka Electronic, Köln, Germany). Tewameter ${ }^{\circledR}$ probe measures indirectly the density gradient of water evaporation over the skin surface using two pairs of sensors (temperature and relativehumidity) in an "open chamber" configuration mode. The Fick diffusion law is the basis for the measurement allowing to calculate the evaporation rate in $\mathrm{g} \cdot \mathrm{h}-1 \cdot \mathrm{m}-2$. The measurement was taken in the centre of the right cheek. Precautions were taken in order to avoid any turbulence in the measurement area. According to the technical Guide, the scale is as follows: 0-10 (very healthy conditions), 10-15 (healthy conditions), 15-25 (normal condition), 25-30 (affected skin) and > 30 (critical condition).

\subsubsection{Measurement of skin sebum content}

Skin sebum content, in the centre of the forehead, was measured using a Sebumeter ${ }^{\circledR}$ SM 815 (Courage+Khazaka Electronic, Köln, Germany). Sebumeter ${ }^{\circledR}$ measurement is based on "greasy spot photometry". When the mat tape of the Sebumeter ${ }^{\circledR}$ cartridge is brought into contact with skin (over a $64 \mathrm{~mm} 2$ surface) it becomes transparent according to the skin sebum content. The transparency (light transmission) of the mat tape is measured by a photocell allowing to calculate the skin sebum content in $\mu \mathrm{g} / \mathrm{cm} 2$.

\subsubsection{Measurement of skin elasticity and firmness}

Skin elasticity was measured using a Cutometer® MPA 580 (Courage+Khazaka Electronic, Köln, Germany) skin viscoelasticity analyser. The skin surface of the face (right cheek) was drawn into the aperture $(3 \mathrm{~mm})$ of the probe by a negative pressure $(450 \mathrm{mbar})$ for $3 \mathrm{sec}$ and thereafter released for $3 \mathrm{sec}$. The penetration depth of the skin inside the probe, during the suction and the release phase was measured by a non-contact optical measuring system. R0 and R2 elasticity parameters were measured. R0 is known as the first maximum amplitude of the first suction curve (Uf, skin distensibility), representing the passive behaviour of the skin to force. R0 is linked with the stretching of both collagen and elastic fibres and is inversely proportional to their thickness and rigidity. R2 is known as the skin "gross" or "overall" elasticity and is represented by the ratiobetween the "residual deformation" (Ua) and its maximum "distensibility" (Uf). R2 is a relative elasticity parameter widely used to assess skin elasticity and ageing.

\subsubsection{Measurement of skin colour (melanin content) and skin radiance}

Skin melanin content was indirectly evaluated by measuring skin colour components related to melanin content by colourimetry. The Individual Typology Angle (ITA ${ }^{\circ}$ ) by means of $L^{*}$ and $b^{*}$ skin colour measurement using a Colourimeter CM-700D (Konica Minolta, Milan, Italy) was calculated. ITA $^{\circ}$ measurement is based on the measurement of $L^{*}$ and $b^{*}$ colour components measurement by a skin colourimeter. $\mathrm{ITA}^{\circ}$ w as then calculated as follows: $\operatorname{ITA}^{\circ}=\left[\operatorname{ArcTan}\left(\left(\mathrm{L}^{*}-50\right) / \mathrm{b}^{*}\right)\right] \times 180 / \pi$. Bases on ITA $^{\circ}$ values, skin colour can be classified as follows: ITA $>55^{\circ}$ very light skin colour, $55 \geq$ ITA $^{\circ}>41$ light skin colour, $41 \geq \mathrm{ITA}^{\circ}>28$ intermediate skin colour, $28 \geq \mathrm{ITA}^{\circ}>10 \mathrm{tan} / \mathrm{matt}$ skin colour. Individual The more $\operatorname{ITA}^{\circ}$ is increased, the lighter the skin.

Skin radiance was evaluated by measuring the gloss values with a Colourimeter CM-700D (Konica Minolta, Milan, Italy). The $\mathrm{d}: 8^{\circ}$ geometry of the colourimeter features an optical device providing diffuse illumination (Ulbricht sphere). The light (Xenon lamp) is projected into a sphere coated with a white highly reflecting substance (barium sulphate, ceramic, special plastic) which 
reflects the light manifold. A shutter inside the sphere prevents the directional rays from reaching the measuring sample directly. The skin area to be measured is positioned at an opening of the sphere and is illuminated from all directions with a close to perfect diffuse light. The sensor view s the surface being measured through an opening at the top of the sphere with an angle of $8^{\circ}$ to the vertical axis. In order to prevent the reflection of specular light from the sample surface, the instrument features a gloss trap. When the trap, which is arranged with an angle of $-8^{\circ}$ to the viewing opening, is opened, the light which would otherwise be reflected from the interior wall of the sphere is eliminated and can therefore not illuminate the sample. The relation betw een directional and diffuse reflection allows calculating the gloss component. The measurement was taken in the cheek.

\subsection{Subjective Self-Assessment of the efficacy of the Product}

The subject-based evaluation of the efficacy of the tested product w as performed using a 12-item questionnaire adapted to the investigated product and completed by all the study participants at week 4 and at the end of the study (week 12). For each item, answers were recorded on a 4 -point grading scale (completely agree, agree, disagree and completely disagree) and results were expressed as the percentage of subjects in agreement.

\subsection{Sample size}

The sample size w as calculated, for the long-term study, with a two-sided $5 \%$ significance level and a power of $80 \%$ taking into account a $20 \%$ variation of the primary endpoints due to both interindividual human variability and error in the measurement techniques. Sample size was calculated using PASS 11 statistical softw are (version 11.0.8 for Windows) running on Windows Server 2008 R2 Standard SP1 64-bit edition (Microsoft, USA). A sample size of 20 subjects per group was neces sary given an anticipated dropout rate of $20 \%$.

\subsection{Randomisation}

A restricted randomisation list w as created using PASS11 (version 11.0.8; PASS, LLC. Kaysville, UT, USA) statistical software running on Windows Server 2008 R2 Standard SP1 64-bit edition (Microsoft, USA) by a biostatistician and stored in a safe place. The randomisation sequence was stratified using "Efron's biased coin" algorithm with a 1:1 allocation ratio. The allocation sequence was concealed from the study director in sequentially numbered, opaque, and sealed envelopes, reporting the unblinded treatment allocation (based on subject entry number in the study). The A4 sheet reporting the unblinded treatment $\mathrm{w}$ as folded to render the envelope impermeable to intense light. After acceptance of the subject in the study, the appropriate numbered envelope was opened. An independent technician dispensed either dietary supplement or placebo products according to the card inside the envelope. The study adhered to established procedures to maintain separation between the investigator and its collaborators and the staff that delivered the intervention. Staff who delivered the intervention did not take outcome measurements. Subjects, investigators and collaborators were kept masked to product assignment. The dietary supplement and placebo products were in capsule form and identical in appearance. They were prepacked in blisters and consecutively numbered for each subject according to the randomisation schedule. Each subject was assigned an order number and received the capsules in the corresponding prepacked blister.

\subsection{Safety.}

The occurrence of adverse events (AEs) was monitored throughout the study by the investigators and based on subjects' diary entries. Investigators rated the observed and repor ted AEs as being either severe or non-severe based upon their potential relationship to study treatment. 


\subsection{Statistical methods}

Statistical analysis was performed using NCSS 8 (version 8.0.4 for Windows; NCSS, Kaysville, UT, USA) running on Windows Server 2008 R2 Standard SP1 64-bit edition (Microsoft, USA). Data normality was checked using Shapiro-Wilk W normality test and data shape. Both intragroup (vs. baseline) and intergroup (between treatments) statistical analysis was carried out two-way t test of student. A p $<0.05 \mathrm{w}$ as considered statistically significant. Statistical analy sis output was reported as follow s: ${ }^{*} \mathrm{p}<0.05,{ }^{* *} \mathrm{p}<0.01$, and ${ }^{* * *} \mathrm{p}<0.001$.

\section{Results}

A total of 100 female subjects were successfully randomised and all of them completed the full course of treatment and follow -up (Figure 2). Data analysis w as intention-to-treat and involved all subjects who were randomly assigned. Subjects' compliance to treatment was assessed through product accountability, as follows: at each visit, the expected amount of consumed capsule was compared with the amount dispensed minus the amount the subject returned. No major deviation was observed in the treatment regimen. All subjects were included in the safety analysis data set. Subjects attended clinic visits at the time of randomisation (baseline) and after 2, 4, 8, 12 weeks of product use. All the tested products were well tolerated. No adverse reactions occurred during the study period.

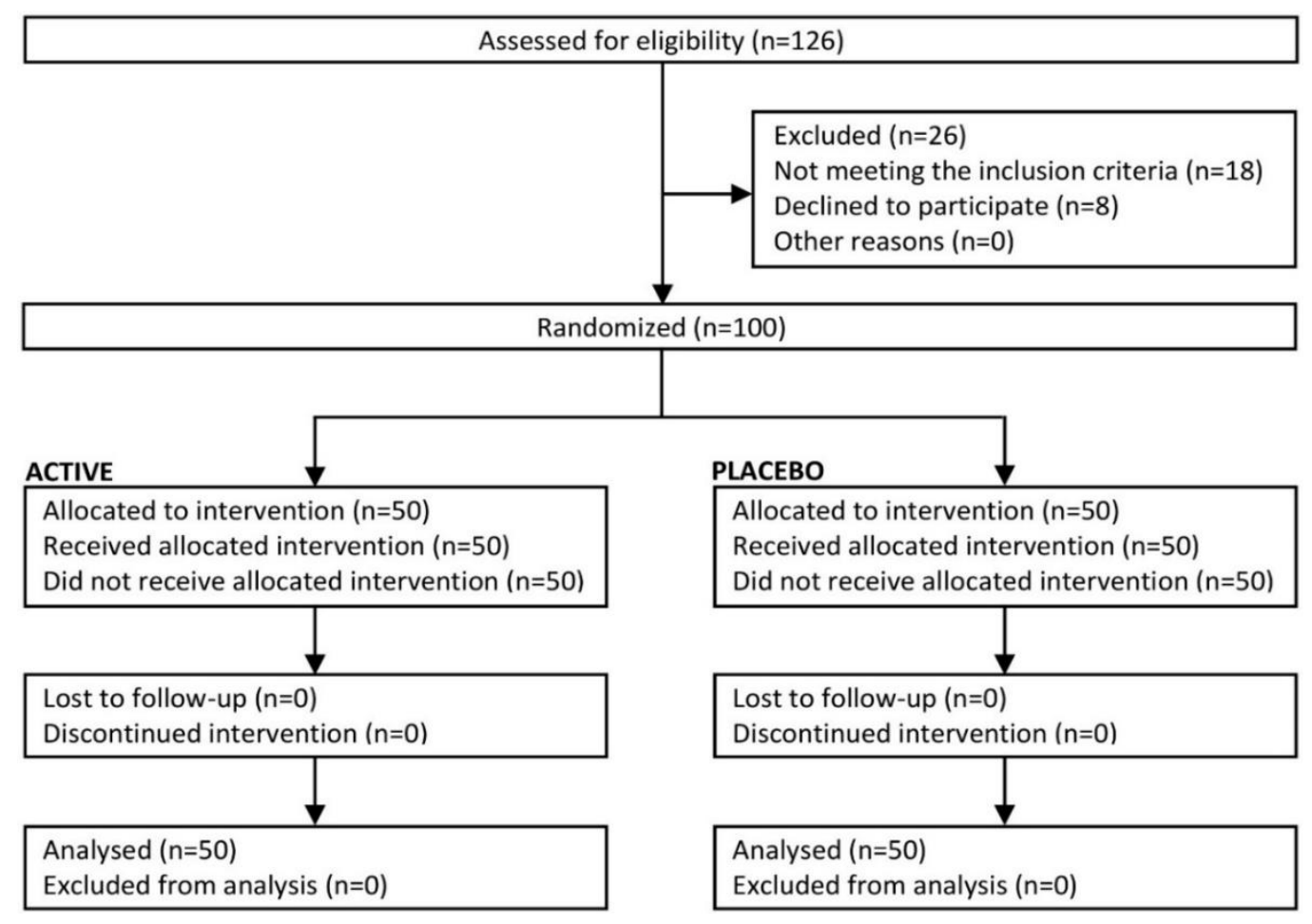

Figure 2. Flow chart of inclusion of subjects.

Demographic and baseline characteristics (Table 1) were similar across treatment arms, indicating unbiased randomisation and the absence of covariates. The mean age of volunteers in the study was $50.6 \pm 1.0$ years being the minimum age 35 years old and the maximum age 65 years old. Regarding the gender, $100 \%$ of participants were women. The population was $50 \%$ Caucasian and $50 \%$ Asian and the $50 \%$ of them had sensitive skin type based on lactic acid stinging test. 
Table 1. Demographic and ba seline characteristics of study participants.

\begin{tabular}{|c|c|c|c|c|c|c|}
\hline & \multicolumn{3}{|c|}{ Treatment group } & \multicolumn{3}{|c|}{ Placebo group } \\
\hline & Asian & Caucasian & Overall & Asian & Caucasian & Overall \\
\hline \multicolumn{7}{|l|}{ Sex } \\
\hline Male (N) & 0 & 0 & 0 & 0 & 0 & 0 \\
\hline Female (N) & 25 & 25 & 50 & 25 & 25 & 50 \\
\hline Age (years) & $48.3 \pm 1.1$ & $52.7 \pm 1.3$ & $50.5 \pm 0.9$ & $49.7 \pm 1.2$ & $51.9 \pm 1.6$ & $50.8 \pm 1.0$ \\
\hline Sensitive skin $(\%)$ & $48 \%$ & $52 \%$ & $50 \%$ & $52 \%$ & $48 \%$ & $50 \%$ \\
\hline Smokers (\%) & $4 \%$ & $20 \%$ & $12 \%$ & $0 \%$ & $16 \%$ & $8 \%$ \\
\hline Skin moisturization (a.u & $46.2 \pm 2.1$ & $34.4 \pm 1.4$ & $40.3 \pm 1.5$ & $40.7 \pm 1.8$ & $37.7 \pm 1.6$ & $39.2 \pm 1.2$ \\
\hline TEWL $\left(\mathrm{g} \cdot \mathrm{h}^{-1} \cdot \mathrm{m}^{-2}\right)$ & $17.6 \pm 1.0$ & $11.3 \pm 0.5$ & $14.5 \pm 0.7$ & $17.7 \pm 0.9$ & $11.9 \pm 0.5$ & $14.8 \pm 0.6$ \\
\hline Wrinkle depth $(\mu \mathrm{m})$ & $269.7 \pm 19.6$ & $299.7 \pm 20.9$ & $284.7 \pm 14.3$ & $252.4 \pm 13.8$ & $270.7 \pm 23.1$ & $261.6 \pm 13.4$ \\
\hline $\operatorname{Ra}(\mu \mathrm{m})$ & $27.9 \pm 1.4$ & $30.7 \pm 1.0$ & $29.3 \pm 0.9$ & $27.2 \pm 1.6$ & $30.3 \pm 0.9$ & $28.8 \pm 0.9$ \\
\hline R2 (Ua/Uf) & $0.5598 \pm 0.0136$ & $0.6686 \pm 0.0135$ & $0.6142 \pm 0.0123$ & $0.5419 \pm 0.0151$ & $0.6208 \pm 0.0190$ & $0.5814 \pm 0.0133$ \\
\hline R0 (Uf) (mm) & $0.3279 \pm 0.0190$ & $0.3500 \pm 0.056$ & $0.3389 \pm 0.0099$ & $0.3491 \pm 0.0130$ & $0.3578 \pm 0.0092$ & $0.3535 \pm 0.0079$ \\
\hline $\operatorname{ITA}^{\circ}\left({ }^{\circ}\right)$ & $42.0 \pm 1.7$ & $31.9 \pm 1.4$ & $37.0 \pm 1.3$ & $43.0 \pm 1.5$ & $32.2 \pm 1.3$ & $37.6 \pm 1.2$ \\
\hline Skin radiance (a.u) & $5.7 \pm 0.3$ & $10.8 \pm 0.3$ & $8.2 \pm 0.4$ & $6.3 \pm 0.2$ & $11.6 \pm 0.4$ & $8.9 \pm 0.5$ \\
\hline Sebum content $\left(\mu \mathrm{g} / \mathrm{cm}^{2}\right)$ & $100.9 \pm 4.5$ & $153.8 \pm 13.4$ & $127.4 \pm 8.0$ & $110.6 \pm 4.1$ & $174.3 \pm 14.0$ & $142.5 \pm 8.5$ \\
\hline $\operatorname{MDA}(\mu \mathrm{M})$ & $2.7 \pm 0.1$ & $2.5 \pm 0.1$ & $2.6 \pm 0.1$ & $2.7 \pm 0.1$ & $2.5 \pm 0.1$ & $2.6 \pm 0.1$ \\
\hline TAS $\left(\mu \mathrm{M} \mathrm{Fe}^{2+}\right)$ & $446.5 \pm 12.4$ & $430.5 \pm 16.6$ & $438.5 \pm 10.3$ & $440.3 \pm 11.2$ & $419.2 \pm 18.7$ & $429.7 \pm 10.9$ \\
\hline
\end{tabular}

Throughout the study period, environmental conditions (temperature, UV radiation, humidity) and air quality (PM 10, $\mathrm{PM} 2.5, \mathrm{SO}_{2}, \mathrm{NO}_{2} \mathrm{O}_{3}$ and benzene) were recorded. During the days when the clinical trial was conducted, elevated PM10 and PM2.5 concentrations in the respective urban areas were registered (Agenzia Regionale per la Protezione dell'ambiente della Lombardia). Study population were exposed to PM 10 air pollutant concentrations above WHO air quality guidelines (> $20 \mu \mathrm{g} / \mathrm{m} 3$ ) during $90 \%$ of the study time and above $50 \mu \mathrm{g} / \mathrm{m} 3$ during $36 \%$ of the time. The exposure to fine particulate matter (PM 2.5) was even worse, surpassing the WHO healthy limits $(10 \mu \mathrm{g} / \mathrm{m} 3)$ $96 \%$ of the time and above the $25 \mu \mathrm{g} / \mathrm{m} 3$ limit $60 \%$ of the time. The PM 10 and PM 2.5 aver age during the period was $45 \pm 21 \mu \mathrm{g} / \mathrm{m} 3$ and $35 \pm 21 \mu \mathrm{g} / \mathrm{m} 3$, respectively. The daily mean value of the major air quality parameters, throughout the study period, can be seen in the supplementary information.

\subsection{Effects on skin and systemic oxidative status}

3.1.1 Skin Lipid Peroxidation (LPO) Through Malondialdehyde (MDA) Measurement.

A statistically significant decrease of the basal LPO content $w$ as observed both in Caucasian and Asian subjects (Figure. 3). The overall MDA content in the skin horny layer was decreased by 5.2 $(\mathrm{p}=0.0025), 7.5(\mathrm{p}=0.0000)$ and $10.0 \%(\mathrm{p}=0.0000)$, after 4,8 , and $12 \mathrm{w}$ eeks of treatment $\mathrm{w}$ ith the dietary supplement; respectively. In the subpopulations, the MDA content decreased in Caucasian subjects by $5.5(\mathrm{p}=0.0350), 7.9(\mathrm{p}=0.0042)$ and $10.5 \%(\mathrm{p}=0.0026)$, after 4,8 , and 12 w eeks treatment; respectively. As for the Asian volunteers, MDA content decreased by $5.0(p=0.0350), 7.1 \quad(p=0.0042)$ and 9.5\% $(\mathrm{p}=0.0026)$, after 4,8 , and 12 weeks treatment; respectively. No statistically significant differences were observed when comparing Asian and Caucasian subjects. Statistical significance in the intergroup analysis of MDA content was only detected at the end of the study in the whole study population (Asian and Caucasian subjects) $(\mathrm{p}=0.0047)$ and in the Caucasian subjects $(\mathrm{p}=0.0463)$. On the other hand, MDA content was unchanged in the placebo-treated subjects throughout the study 


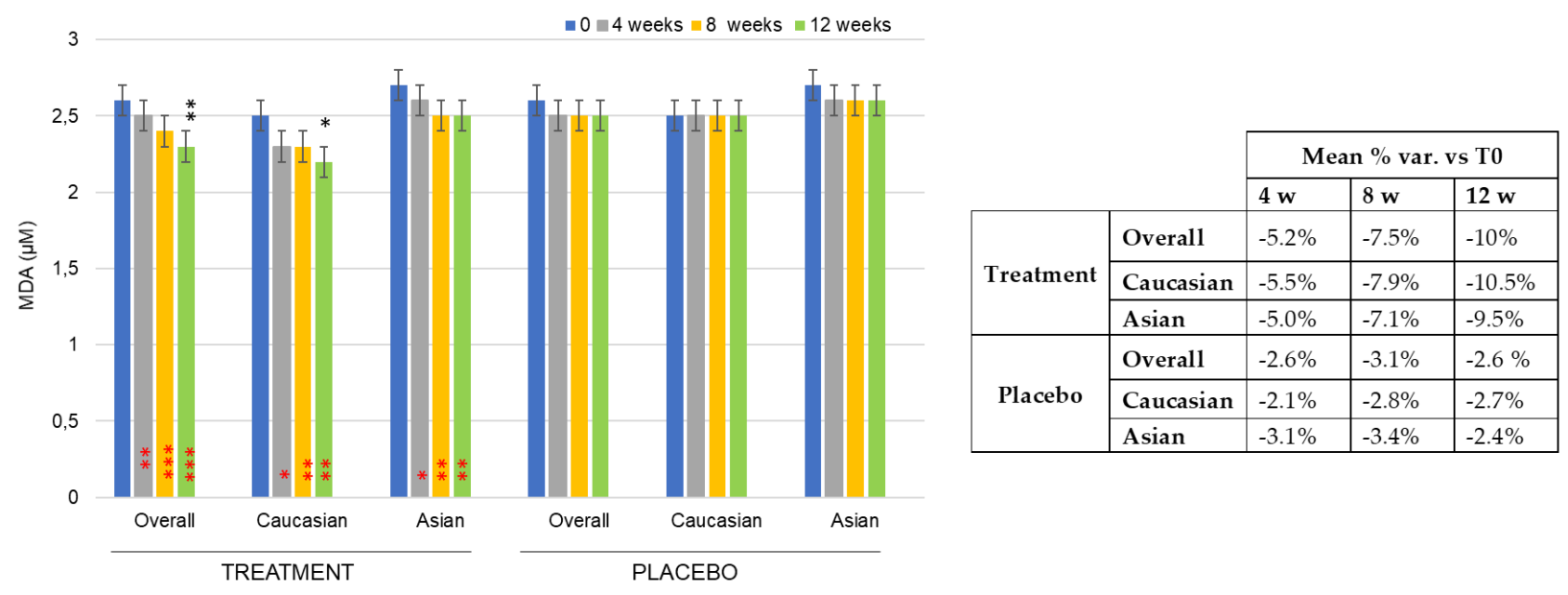

Figure 3: Lipid-peroxidation (LPO) le vels measured by MDA content on the skin cells before and after 4,8 , and 12 weeks treatment. Intragroup (vs. 0) statistical analysis is reported inside the bars of the histogram (in red). Intergroup (vs. placebo) statistical analysis is reported upon the bars of the histogram. Statistical analysis is reported as follows: ${ }^{*} p<0.05,{ }^{* *} p<0.01$, and ${ }^{* * *} p<0.001$. Data are means $(\mu \mathrm{M}) \pm S E M$. In the table is re ported the percentage variation vs. ba seline.

\subsubsection{Total antioxidant capacity of saliva (TAS).}

A statistically significant increase of TAS was observed both in Caucasian and Asian subject's treatment group (Figure. 4). The overall (Caucasian and Asian subjects) TAS increase was by 21.7 $(p=0.0025)$ and $35.0 \%(p=0.0000)$, after 4 and 12-weeks treatment; respectively. TAS increase in Caucasian subjects was by $22.1(\mathrm{p}=0.0020)$ and 35.2\% ( $\mathrm{p}=0.0000)$, after 4 and 12 weeks; respectively. TAS increase in Asian subjects was by $21.3(\mathrm{p}=0.0000)$ and 34.7\% (p=0.0000), after 4 and 12 weeks; respectively. No statistically significant differences were observed between Asian and Caucasian subjects in the \% variation. The TAS variation observed in the dietary supplement group was statistically significant when compared to the placebo treatment regimen, both overall (Caucasian and Asian subjects) and when considering only Caucasian or Asian subjects, at all the investigated checkpoints. How ever, TAS was unchanged in the placebo-treated subjects throughout the study.

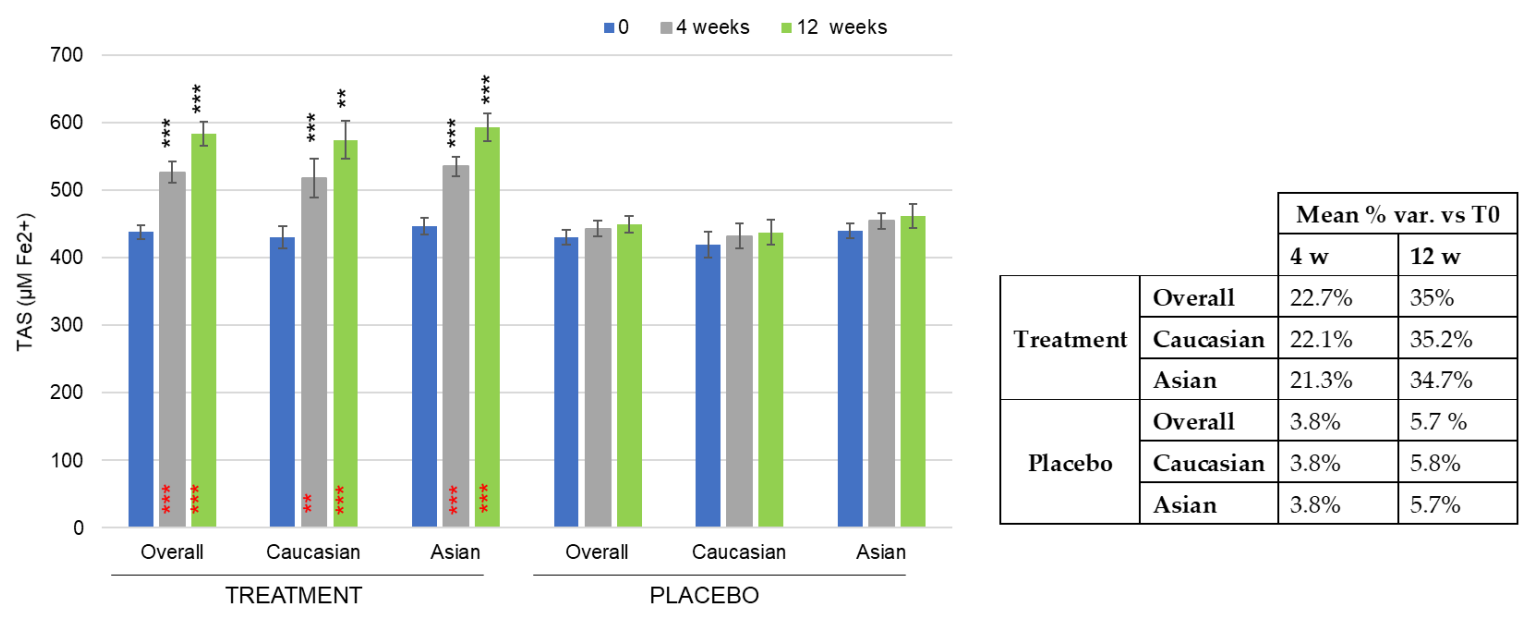

Figure 4: Total antioxidant capacity of saliva (TAS) measured by FRAP te chnique before and after 4- and 12-weeks treatment. Intragroup (vs. 0) statistical analysis is reported inside the bars of the histogram (in red). Intergroup (vs. placebo) statistical analysis is reported upon the bars of the histogram. Statistical analysis is reported as follows: ${ }^{*} p<0.05,{ }^{* *} p<0.01$, and ${ }^{* * *} p<0.001$. Data are means $(\mu \mathrm{M} \mathrm{Fe} 2+) \pm \mathrm{SEM}$. In the table is reported the percentage variation vs. baseline 


\subsection{Effects on Facial Skin Condition}

\subsubsection{Transepidermal water loss (TEWL)}

Changes in the epidermal barrier function were evaluated by measuring the TEWL. A statistically significant decrease of TEWL was observed in all the treatment groups (Table. 2). The overall (Caucasian and Asian subjects) TEWL decrease was by 3.8 ( $p=0.0001), 6.2(p=0.0000), 9.2$ $(p=0.0000)$ and $10.1 \%(p=0.0000)$, after $2,4,8$, and 12 weeks of treatment, respectively. TEWL decrease in Caucasian subjects w as by $3.5(\mathrm{p}=0.0011), 5.2(\mathrm{p}=0.0001), 8.7(\mathrm{p}=0.0000)$ and $8.6 \%(\mathrm{p}=0.0000)$, after $2,4,8$, and 12 weeks of treatment; respectively. TEWL decrease in Asian subjects was by 4.1 $(p=0.0099), 7.3(p=0.0000), 9.7(p=0.0001)$ and 11.6\% ( $p=0.0000)$, after 2, 4, 8, and 12 w eeks of treatment; respectively. Although the Asian panel appears to have a greater decrease in TEWL at the end of the study, the differences are not statistically significant compared to the Caucasian group. The TEWL variation observed in the treatment group was statistically significant, when compared to the placebo, both overall (Caucasian and Asian subjects) at all the investigated checkpoints and when only considering Caucasian or Asian subjects, starting from 4 weeks product use. In the placebo group a slight decrease of the TEWL was observed $(-2.3 \%$ at the end of the study)

Table 2: Effects on Transepidermal water loss (TEWL) and on skin moisture (water content) in facial skin

\begin{tabular}{|c|c|c|c|c|c|c|c|}
\hline & \multicolumn{2}{|c|}{ Groups } & \multicolumn{5}{|c|}{ Intervention Period } \\
\hline & & & 0 weeks & 2 weeks & 4 weeks & 8 weeks & 12 weeks \\
\hline \multirow{6}{*}{$\begin{array}{l}\text { TEWL } \\
\left(\mathrm{g} / \mathrm{m}^{2} / \mathrm{h}\right)\end{array}$} & \multirow{3}{*}{ Treatment } & Overall & $14.5 \pm 0.7$ & $\begin{array}{c}13.9 \pm 0.7^{* * *} \\
(-3.8 \%)^{S}\end{array}$ & $\begin{array}{c}13.5 \pm 0.6^{* * *} \\
(-6.2 \%)^{s}\end{array}$ & $\begin{array}{c}13.0 \pm 0.6^{* * *} \\
(-9.2 \%)^{S}\end{array}$ & $\begin{array}{c}12.8 \pm 0.6^{* * *} \\
(-10.1 \%)^{\varsigma}\end{array}$ \\
\hline & & Caucasian & $11.3 \pm 0.5$ & $\begin{array}{c}10.9 \pm 0.4^{* *} \\
(-3.5 \%)\end{array}$ & $\begin{array}{c}10.7 \pm 0.4^{* * *} \\
(-5.2 \%)^{\int}\end{array}$ & $\begin{array}{c}10.2 \pm 0.4^{* * *} \\
(-8.7 \%)^{\int}\end{array}$ & $\begin{array}{c}10.2 \pm 0.3^{* * *} \\
(-8.6 \%)^{\int}\end{array}$ \\
\hline & & Asian & $17.6 \pm 1.0$ & $\begin{array}{c}17.0 \pm 1.0^{* * *} \\
(-4.1 \%)\end{array}$ & $\begin{array}{c}16.3 \pm 0.9^{* * *} \\
(-7.3 \%)^{\varsigma} \\
\end{array}$ & $\begin{array}{c}15.7 \pm 0.8^{* * *} \\
(-9.7 \%)^{\varsigma} \\
\end{array}$ & $\begin{array}{c}15.4 \pm 0.8^{* * *} \\
(-11.6 \%)^{\varsigma} \\
\end{array}$ \\
\hline & \multirow{3}{*}{ Placebo } & Overall & $14.8 \pm 0.6$ & $\begin{array}{c}14.5 \pm 0.6^{*} \\
(-1.5 \%)\end{array}$ & $\begin{array}{c}14.3 \pm 0.6^{* * *} \\
(-2.8 \%)\end{array}$ & $\begin{array}{c}14.3 \pm 0.6^{* *} \\
(-2.7 \%)\end{array}$ & $\begin{array}{c}14.4 \pm 0.6^{* *} \\
(-2.3 \%)\end{array}$ \\
\hline & & Caucasian & $11.9 \pm 0.5$ & $\begin{array}{c}11.7 \pm 0.4^{* *} \\
(-1.8 \%)\end{array}$ & $\begin{array}{c}11.6 \pm 0.4^{* * *} \\
(-2.6 \%)\end{array}$ & $\begin{array}{c}11.6 \pm 0.4^{* * *} \\
(-2.6 \%)\end{array}$ & $\begin{array}{c}11.5 \pm 0.4^{* * *} \\
(-3.3 \%)\end{array}$ \\
\hline & & Asian & $17.7 \pm 0.9$ & $\begin{array}{c}17.4 \pm 0.8 \\
(-1.3 \%) \\
\end{array}$ & $\begin{array}{c}17.0 \pm 0.8^{* *} \\
(-3.1 \%) \\
\end{array}$ & $\begin{array}{c}17.0 \pm 0.7^{*} \\
(-2.8 \%) \\
\end{array}$ & $\begin{array}{c}17.7 \pm 0.7 \\
(-1.4 \%) \\
\end{array}$ \\
\hline \multirow{6}{*}{$\begin{array}{l}\text { Water } \\
\text { Content } \\
\text { (a.u.) }\end{array}$} & \multirow{3}{*}{ Treatment } & Overall & $40.3 \pm 1.5$ & $\begin{array}{c}42.5 \pm 1.6^{* * *} \\
(+5.7 \%)^{\varsigma}\end{array}$ & $\begin{array}{c}43.7 \pm 1.6^{* * *} \\
(+9.0 \%)^{\varsigma}\end{array}$ & $\begin{array}{c}44.7 \pm 1.5^{* * *} \\
(+12.3 \%)^{\varsigma}\end{array}$ & $\begin{array}{c}45.6 \pm 1.4^{* * *} \\
(+14.8 \%)^{\jmath}\end{array}$ \\
\hline & & Caucasian & $34.4 \pm 1.4$ & $\begin{array}{c}36.0 \pm 1.3^{* *} \\
(+5.0 \%)^{\varsigma}\end{array}$ & $\begin{array}{c}36.8 \pm 1.3^{* * *} \\
(+7.4 \%)^{f}\end{array}$ & $\begin{array}{c}38.0 \pm 1.2^{* * *} \\
(+11.4 \%)^{\varsigma}\end{array}$ & $\begin{array}{c}39.1 \pm 1.1^{* * *} \\
(+15.1 \%)^{\varsigma}\end{array}$ \\
\hline & & Asian & $46.2 \pm 2.1$ & $\begin{array}{c}49.0 \pm * 2.3^{* * *} \\
(+6.5 \%)^{\jmath}\end{array}$ & $\begin{array}{c}50.7 \pm 2.1^{* * *} \\
(+10.6 \%)^{\varsigma}\end{array}$ & $\begin{array}{c}51.4 \pm 1.9^{* * *} \\
(+13.2 \%)^{\varsigma}\end{array}$ & $\begin{array}{c}52.1 \pm 1.9^{* * * *} \\
(+14.5 \%)^{\varsigma}\end{array}$ \\
\hline & \multirow{3}{*}{ Placebo } & Overall & $39.2 \pm 1.2$ & $\begin{array}{c}39.4 \pm 1.1 \\
(+1.2 \%)\end{array}$ & $\begin{array}{c}40.4 \pm 1.2^{* * *} \\
(+3.5 \%)\end{array}$ & $\begin{array}{c}41.2 \pm 1.2^{* * *} \\
(+5.8 \%)\end{array}$ & $\begin{array}{c}41.0 \pm 1.1^{* * *} \\
(+5.3 \%)\end{array}$ \\
\hline & & Caucasian & $37.7 \pm 1.6$ & $\begin{array}{c}38.5 \pm 1.6^{* * *} \\
(+2.3 \%)\end{array}$ & $\begin{array}{c}39.0 \pm 1.6^{* * *} \\
(+3.8 \%)\end{array}$ & $\begin{array}{c}39.3 \pm 1.6^{* * *} \\
(+4.5 \%)\end{array}$ & $\begin{array}{c}39.3 \pm 1.5^{* * *} \\
(+4.8 \%)\end{array}$ \\
\hline & & Asian & $40.7 \pm 1.8$ & $\begin{array}{c}40.3 \pm 1.6 \\
(+0.0 \%)\end{array}$ & $\begin{array}{l}41.7 \pm 1.7 \\
(+3.3 \%)\end{array}$ & $\begin{array}{c}43.2 \pm 1.7^{* * *} \\
(+7 \%)\end{array}$ & $\begin{array}{c}42.7 \pm 1.6^{* * *} \\
(+5.8 \%)\end{array}$ \\
\hline
\end{tabular}

Data are mean \pm SEM. In brackets is reported the percentage variation vs. baseline. Intragroup (vs. baseline) statistical analysis is reported as follows: ${ }^{*} \mathrm{p}<0.05,{ }^{* *} \mathrm{p}<0.01$, and ${ }^{* * *} \mathrm{p}<0.001$. S Statistically different vs. placebo.

\subsubsection{Skin moisturization (Water content).}

A statistically significant increase of the skin moisture content was observed both in Caucasian and Asian subjects (Table 2). The overall (Caucasian and Asian subjects) skin moisturization increase was by $5.7(p=0.0001), 9.0(p=0.0000), 12.3(p=0.0000)$ and 14.8\% ( $=0.0000)$, after 2, 4, 8, and 12 weeks treatment; respectively. Skin moisturization increase in Caucasian subjects w as by $5.0(p=0.0000), 7.4$ $(p=0.0000), 11.4(p=0.0000)$ and $15.1 \%(p=0.0000)$, after $2,4,8$, and 12 w eeks of treatment; respectively. 
Skin moisturization increase in Asian subjects w as by $6.5(\mathrm{p}=0.0067), 10.6(\mathrm{p}=0.0000), 13.2(\mathrm{p}=0.0000)$ and $14.5 \%(\mathrm{p}=0.0000)$, after $2,4,8$, and 12 weeks of treatment; respectively. No statistically significant differences were observed between Asian and Caucasian subjects. A slight increase in water content was observed in the placebo group at the end of the study (5.3\%), how ever the skin moisturization variation observed in the dietary supplement group was significantly higher when compared to the placebo treatment regimen, both overall (Caucasian and Asian subjects) and for Caucasian and Asian subjects, at all the investigated checkpoints.

\subsection{Effect on skin texture parameters}

\subsubsection{Wrinkle depth.}

A statistically significant decrease of wrinkle depth in the 'crow's feet' was observed both in Caucasian and Asian subjects taking the dietary supplement (Figure 5 a) from w eek 2 onw ards. The overall (Caucasian and Asian subjects) w rinkle depth decrease $w$ as by $10.6(\mathrm{p}=0.0000), 14.5(\mathrm{p}=0.0000)$, $18.0(\mathrm{p}=0.0000)$ and $20.3 \%(\mathrm{p}=0.0000)$, after $2,4,8$, and 12 weeks of treatment; respectively. Wrinkle depth decrease in Caucasian subjects was by $12.0(\mathrm{p}=0.0005), 15.4(\mathrm{p}=0.0000), 19.2(\mathrm{p}=0.0000)$ and $21.0 \%(\mathrm{p}=0.0000)$, after $2,4,8$, and 12 weeks of treatment; respectively. Wrinkle depth decrease in Asian subjects w as by $9.3(\mathrm{p}=0.0000), 13.5(\mathrm{p}=0.0000), 16.8(\mathrm{p}=0.0001)$ and $19.7 \%(\mathrm{p}=0.0000)$, after 2,4 , 8 , and 12 weeks of treatment; respectively. No statistically significant differences were observed between Asian and Caucasian subjects' improvement. The w rinkle depth variation observed in the dietary supplement group was statistically significant when compared to the placebo treatment regimen, both overall (Caucasian and Asian subjects) and for Caucasian and Asian subjects, at all the investigated checkpoints. Wrinkle depth was unchanged $(p>0.05)$ in the placebo-treated subjects throughout the study.

\subsubsection{Skin roughness.}

A statistically significant decrease of skin roughness (Ra parameter) was observed both in Caucasian and Asian subjects (Figure $5 \mathrm{~b}$ ). The overall (Caucasian and Asian subjects) skin roughness decrease was by $3.4(\mathrm{p}=0.0067), 4.4(\mathrm{p}=0.0022), 6.2(\mathrm{p}=0.0000)$ and $7.6 \%(\mathrm{p}=0.0000)$, after $2,4,8$, and 12 weeks of treatment; respectively. Skin roughness decrease in Caucasian subjects was by 2.9 $(\mathrm{p}=0.1680), 3.9(\mathrm{p}=0.0547), 5.5(\mathrm{p}=0.0131)$ and $7.9 \%(\mathrm{p}=0.0041)$, after $2,4,8$, and 12 weeks of treatment; respectively. Skin roughness decrease in Asian subjects was by $3.9(\mathrm{p}=0.0043), 4.8(\mathrm{p}=0.0180), 6.9$ $(\mathrm{p}=0.0002)$ and $7.3 \%(\mathrm{p}=0.0003)$, after $2,4,8$, and 12 w eeks of treatment; respectively. No statistically significant differences were observed between Asian and Caucasian subjects. The skin roughness variation observed in the active treatment group was statistically significant when compared to the placebo regimen, as follows: overall (Caucasian and Asian subjects) group after 2, 8 and 12 weeks; for Asian subjects the variation was statistically significant starting from 8 w eeks product use; while for Caucasian subjects the variation was statistically significant after 12 weeks product use. No variations were monitored $(p>0.05)$ in the placebo-treated subjects throughout the study. 

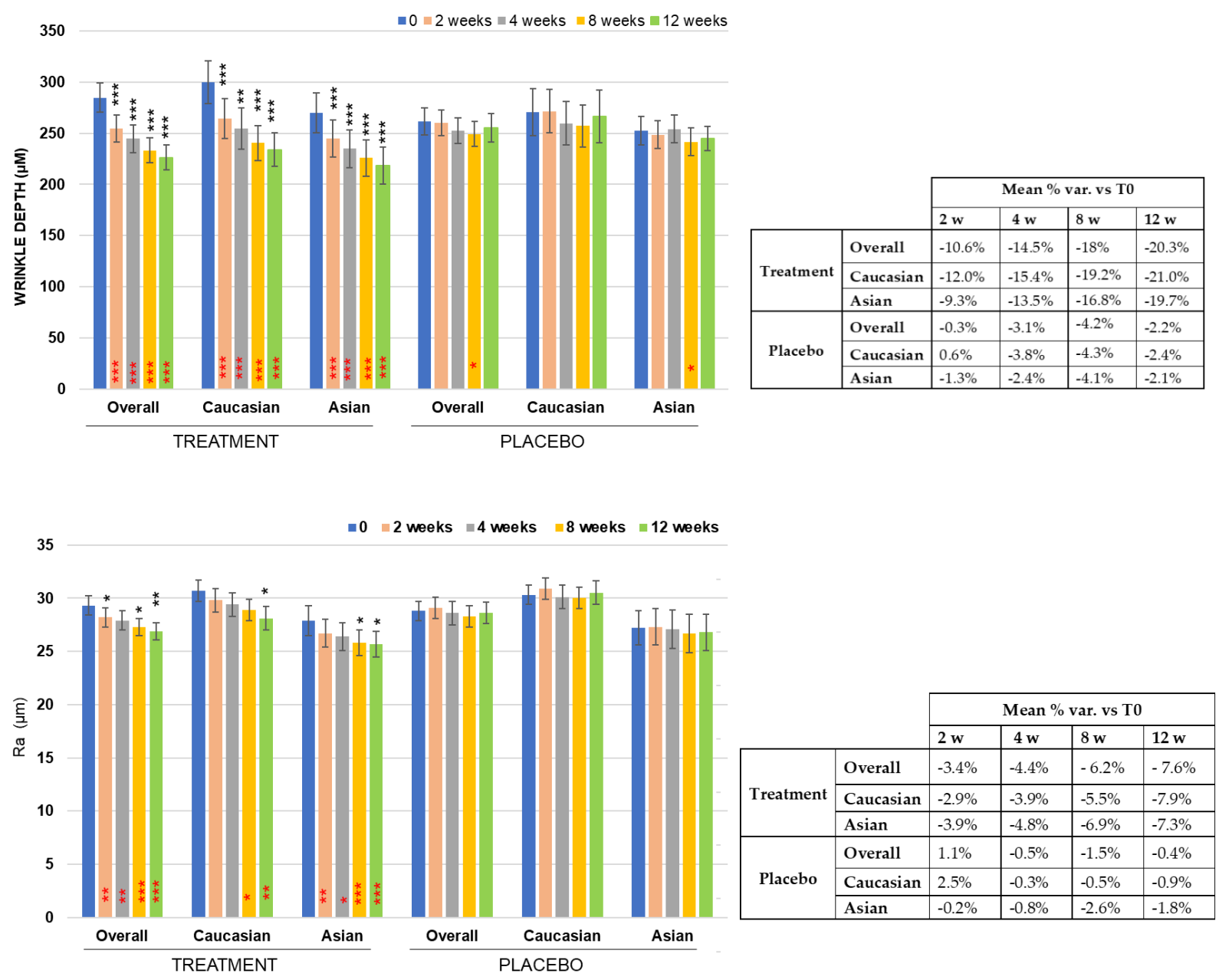

Figure 5: Change on facial skin texture after 2, 4, 8, and 12 weeks of treatment. a) Wrinkles depth variation. b) Skin roughness (Ra parameter). Intragroup (vs.0) statistical analysis is reported inside the bars of the histograms. Intergroup (vs. placebo) statistical analysis is reported upon the bars of the histograms. Statistical analysis is reported as follows: ${ }^{*} \mathrm{p}<0.05,{ }^{* *} \mathrm{p}<0.01$, and ${ }^{* * *} \mathrm{p}<0.001$. Data are means $(\mu \mathrm{m}) \pm S E M$. In the tables a re re ported the percentage variation vs. baseline

\subsection{Effects on skin elasticity}

Results showed that the overall skin firmness and elasticity improved in the course of the study in the treatment group (Table 3).

Skin distensibility, measured as R0 ( $\mathrm{mm})$, significantly decrease in the dietary supplement group (Table. 3). This parameter is related to skin firmness, where decreased R0 indicates increased skin firmness. The overall (Caucasian and Asian subjects) skin distensibility decrease was by 3.8 $(p=0.0000), 4.7(p=0.0000), 6.7(p=0.0000)$ and $7.1 \%(p=0.0000)$, after 2, 4, 8, and 12 weeks of treatment; respectively. Skin distensibility decrease in Caucasian subjects w as by $3.0(p=0.0000), 4.1(p=0.0000)$, $6.1(p=0.0000)$ and $6.8 \%(p=0.0000)$, after $2,4,8$, and 12 weeks of treatment; respectively. Skin distensibility decrease in Asian subjects w as by 4.5 ( $p=0.0001), 5.3(p=0.0006), 7.2(p=0.0000)$ and $7.3 \%$ $(\mathrm{p}=0.0005)$, after $2,4,8$, and 12 w eeks of treatment; respectively. No statistically significant differences were observed between Asian and Caucasian subjects in the active treatment group. How ever, in the placebo group a significant R0 decrease was observed in the Caucasian group, which was not observed in the Asian group. The skin distensibility variation observed in the active group was statistically significant when compared to the placebo treatment regimen, both overall (Caucasian and Asian subjects) and for Caucasian and Asian subjects at all checkpoints. 
The gross elasticity (R2) parameter was significantly increased in the dietary supplement group (Table 3). The overall (Caucasian and Asian subjects) skin gross elasticity increase was by 2.9 $(p=0.0002), 6.1(p=0.0000), 7.1(p=0.0000)$ and 8.0\% ( $p=0.0000)$, after 2, 4, 8, and 12 weeks of treatment; respectively. Skin gross elasticity increase in Caucasian subjects $w$ as by $3.1(p=0.0000), 5.5(p=0.0000)$, $6.6(p=0.0000)$ and $7.6 \%(p=0.0000)$, after $2,4,8$, and 12 weeks of treatment; respectively. Skin gross elasticity increase in Asian subjects was by $2.6(\mathrm{p}=0.1031), 6.8(\mathrm{p}=0.0002), 7.7(\mathrm{p}=0.0000)$ and $8.3 \%$ $(\mathrm{p}=0.0000)$, after $2,4,8$, and 12 weeks of treatment; respectively. The skin gross elasticity variation observed in the dietary supplement group was statistically significant when compared to the placebo treatment regimen, both overall (Caucasian and Asian subjects) at all the investigated checkpoints and for Caucasian and Asian subjects starting from 4 weeks product use. No statistically significant differences were observed between Asian and Caucasian subjects in the active treatment group. However, in the placebo group, while in the Caucasian subgroup there was a significant increase in R0, this parameter was unchanged or even significantly reduced (8 weeks) among Asian subjects.

Table 3: Effects on Skin elasticity

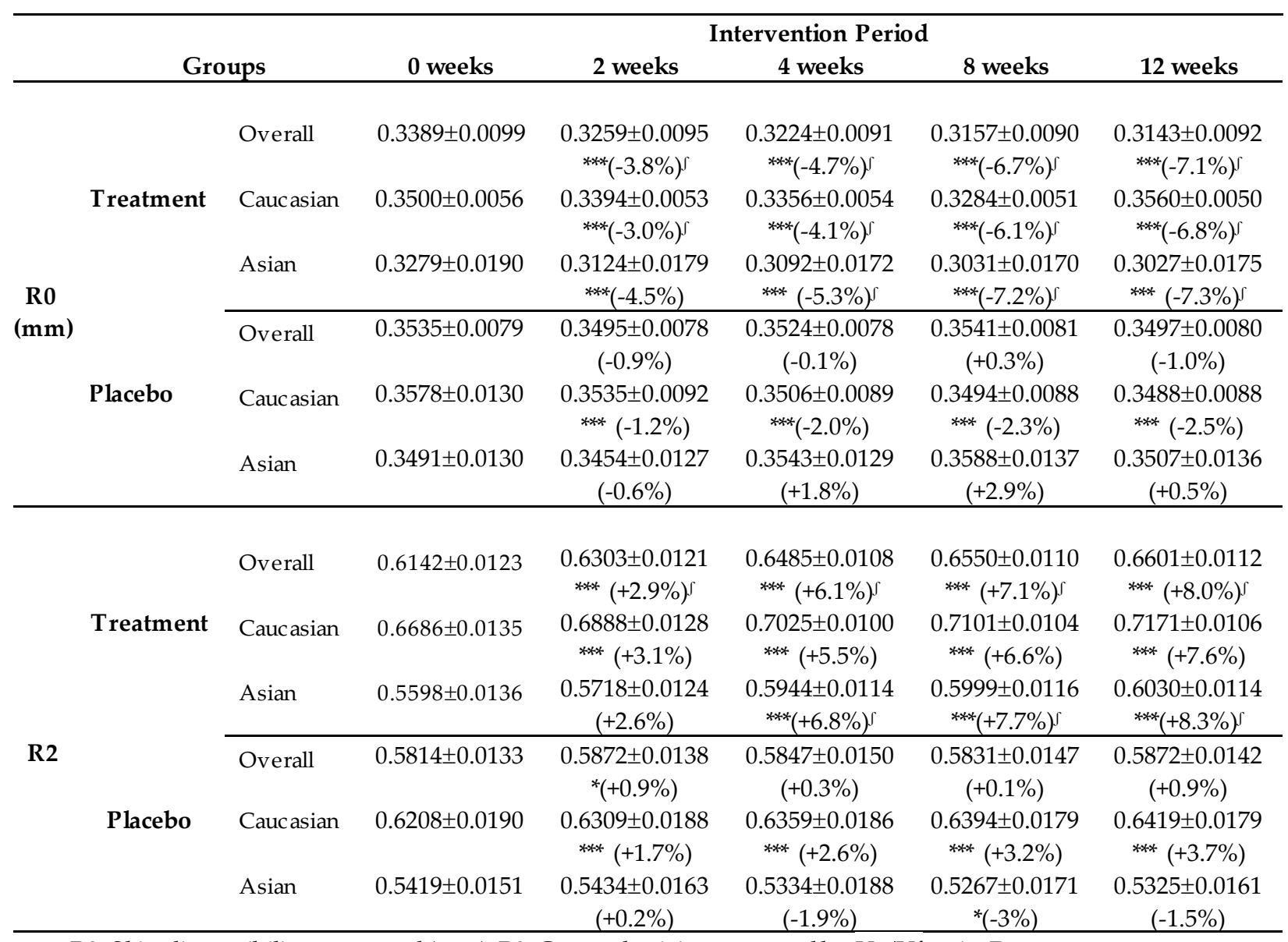

R0: Skin distensibility measured (mm). R2: Gross elasticity measured by Ua/Uf ratio. Da ta a re means \pm SEM. In brackets is reported the percentage varia tion vs. baseline. Intragroup (vs. baseline) statistical analysis is reported as follows: ${ }^{*} \mathrm{p}<0.05,{ }^{* *} \mathrm{p}<0.01$, and ${ }^{* *} \mathrm{p}<0.001$. ${ }^{\text {S }}$ Statistically different vs. placebo.

\subsection{Effects on skin radiance}

Skin gloss, also referred to as skin radiance, was significantly increased both in Caucasian and Asian subjects (Figure 6). The overall (Caucasian and Asian subjects) skin radiance increase was by 8.4\% $(\mathrm{p}=0.0000), 14.6(\mathrm{p}=0.0000), 18.6(\mathrm{p}=0.0000)$ and $20.0 \%(\mathrm{p}=0.0000)$, after $2,4,8$, and 12 weeks of treatment; respectively. Skin radiance increase in Caucasian subjects was by $9.9(\mathrm{p}=0.0000), 16.0$ 
$(p=0.0000), 20.1(p=0.0000)$ and $21.6 \%(p=0.0000)$, after $2,4,8$, and 12 w eeks of treatment; respectively. Skin radiance increase in Asian subjects was by $6.9(p=0.0011), 13.1(p=0.0000), 17.0(p=0.0000)$ and $18.5 \%(p=0.0000)$, after $2,4,8$, and 12 weeks treatment; respectively. The skin radiance variation observed in the dietary supplement group w as statistically significant when compared to the placebo treatment regimen, both overall (Caucasian and Asian subjects), in the Caucasian group at all the investigated checkpoints, and for Asian subjects after 4 weeks of product use.

No significant differences were observed, in the radiance variation, between Asian and Caucasian subjects in the dietary supplement group. However, in the placebo group, while in the Caucasian subgroup there was a significant increase in skin radiance, this parameter was unchanged $(p>0.05)$ among Asian subjects.

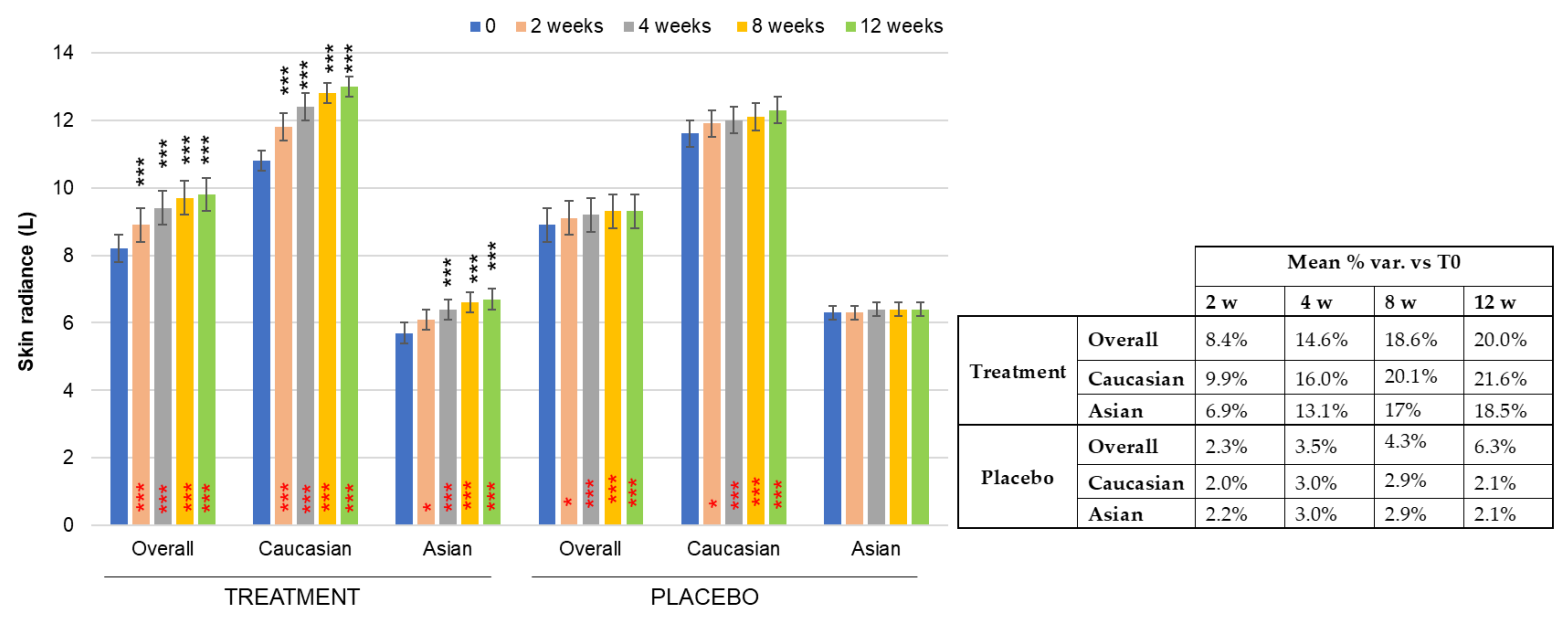

Figure 6: Change on facial skin radiance (L parameter) after 2, 4, 8, and 12 weeks of treatment. Intragroup (vs. 0) statistical analysis is re ported inside the bars of the his togram s (in red). Intergroup (vs. placebo) statistical analysis is reported upon the bars of the histograms. Statistical analysis is reported as follows: ${ }^{*} p<0.05,{ }^{* *} p<0.01$, and ${ }^{* * *} \mathrm{p}<0.001$. Data are presented as the mean of gloss para meter $\pm S E M$ in a rbitrary units (a.u.). In the table is reported the percentage variation vs. baseline.

\subsection{Effects on dark spot pigmentation}

A significant improvement (decrease in intensity of pigmentation) of dark spots, determined by $\mathrm{ITA}^{\circ}$ measurement, w as observed throughout the study both in Caucasian and Asian subjects (Figure 7). The overall (Caucasian and Asian subjects) melanin staining intensity decrease was by 8.2 $(p=0.0032), 12.1 \quad(p=0.0000), 13.9(p=0.0000)$ and 16.4\% $(p=0.0000)$, after 2, 4, 8, and 12 weeks of treatment; respectively. Melanin staining intensity decrease in Caucasian subjects was by 9.3 $(p=0.0002), 12.9(p=0.0000), 16.1(p=0.0000)$ and 19.1\% $(p=0.0000)$, after 2, 4, 8, and 12 weeks of treatment; respectively. Melanin staining intensity decrease in Asian subjects w as by $7.1(p=0.0000)$, $11.3(p=0.0000), 11.6(p=0.0000)$ and 13.8\% ( $p=0.0000)$, after 2, 4, 8, and 12 weeks of treatment; respectively. In the placebo group, the mean variation in the percentage of the ITA measured in the brown spot presented a slight increase at the end of the study (6.6\%), how ever, the melanin staining intensity variation observed in the dietary supplement group was statistically significant when compared to the placebo treatment regimen, both overall (Caucasian and Asian subjects) and for Asian subjects at all checkpoints, and for Caucasian subjects starting from 4 weeks product use. No statistically significant differences were observed between Asian and Caucasian subjects in the ITA ${ }^{\circ}$ variation. 


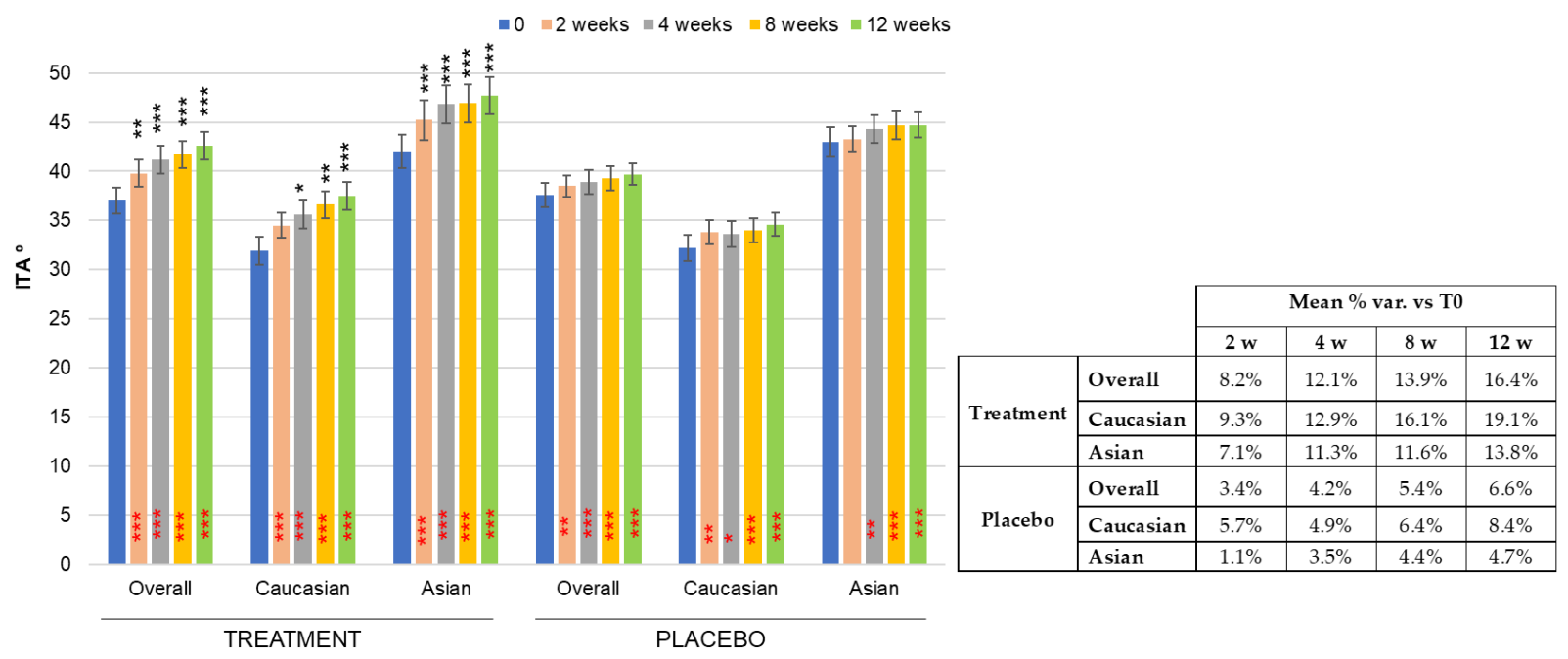

Figure 7: Evolution of dark spot pigmentation, evalua ted with ITA angle, after 2, 4, 8, and 12 weeks of treatment. Intragroup (vs. 0) statistical analysis is reported inside the bars of the histograms (in red). Intergroup (vs. placebo) statistical analysis is reported upon the bars of the histograms. Statistical analysis is reported as follows: ${ }^{*} \mathrm{p}<0.05,{ }^{* *} \mathrm{p}<0.01$, and ${ }^{* *} \mathrm{p}<0.001$. Data are presented as the mean of ITA angle value \pm SEM. In the table is reported the percentage variation vs. baseline.

\subsection{Effect on skin oiliness}

A statistically significant decrease in the skin sebum content was observed both in Caucasian and Asian subjects (Table 4 ). The overall (Caucasian and Asian subjects) skin sebum content decrease was by $3.9(p=0.0010), 5.1(p=0.0001), 9.5(p=0.0000)$ and 10.9\% ( $p=0.0000)$, after 2, 4, 8, and 12 w eeks of treatment; respectively. Skin sebum content decrease in Caucasian subjects w as by $3.8(\mathrm{p}=0.0175)$, $4.6(p=0.0056), 10.1(p=0.0002)$ and $12.0 \%(p=0.0001)$, after 2, 4, 8, and 12 weeks of treatment; respectively. Skin sebum content decrease in Asian subjects w as by $4.0(p=0.0101), 5.6(p=0.0030), 9.0$ $(p=0.0000)$ and $9.8 \%(p=0.0002)$, after $2,4,8$, and 12 weeks of treatment; respectively. No statistically significant differences were observed betw een Asian and Caucasian subjects. The skin sebum content variation observed in the dietary supplement group was statistically significant when compared to the placebo treatment regimen, both overall (Caucasian and Asian subjects) starting from 8 w eeks of product use and for Caucasian subjects after 12 weeks product use.

Table 4: Effects on Skin sebum content

\begin{tabular}{|c|c|c|c|c|c|c|c|}
\hline & \multicolumn{2}{|c|}{ Groups } & \multicolumn{5}{|c|}{ Intervention Period } \\
\hline & & & 0 weeks & 2 weeks & 4 weeks & 8 weeks & 12 weeks \\
\hline \multirow{6}{*}{$\begin{array}{l}\text { Sebum } \\
\text { content } \\
\left(\mu \mathrm{g} / \mathrm{cm}^{2}\right)\end{array}$} & \multirow{3}{*}{ Treatment } & Overall & $127.4 \pm 8.0$ & $\begin{array}{c}121.0 \pm 6.8^{* *} \\
(-3.9 \%)\end{array}$ & $\begin{array}{c}118.6 \pm 6.5^{* * *} \\
(-5.1 \%)\end{array}$ & $\begin{array}{c}113.1 \pm 6.1^{* * *} \\
(-9.5 \%)^{\jmath}\end{array}$ & $\begin{array}{c}111.4 \pm 5.9^{* * * *} \\
(-10.9 \%)^{\varsigma}\end{array}$ \\
\hline & & Caucasian & $153.8 \pm 13.4$ & $\begin{array}{c}145.5 \pm 11.0^{*} \\
(-3.8 \%)\end{array}$ & $\begin{array}{c}142.6 \pm 10.4^{* *} \\
(-4.6 \%)\end{array}$ & $\begin{array}{c}135.1 \pm 9.7^{* * *} \\
(-10.1 \%)\end{array}$ & $\begin{array}{c}132.4 \pm 9.5^{* * *} \\
(-12 \%)^{\varsigma}\end{array}$ \\
\hline & & Asian & $100.9 \pm 4.5$ & $\begin{array}{c}96.5 \pm 4.3^{*} \\
(-4.0 \%) \\
\end{array}$ & $\begin{array}{c}94.6 \pm 4.0^{* *} \\
(-5.6 \%) \\
\end{array}$ & $\begin{array}{c}91.2 \pm 3.9^{* * *} \\
(-9.0 \%) \\
\end{array}$ & $\begin{array}{c}90.4 \pm 4.1^{* *} \\
(-9.8 \%) \\
\end{array}$ \\
\hline & \multirow{3}{*}{ Placebo } & Overall & $142.5 \pm 8.5$ & $\begin{array}{c}140.1 \pm 8.5 \\
(-1.3 \%)\end{array}$ & $\begin{array}{c}137.2 \pm 8.2^{* * *} \\
(-3.3 \%)\end{array}$ & $\begin{array}{c}133.4 \pm 8.1^{* * *} \\
(-5.9 \%)\end{array}$ & $\begin{array}{c}132.4 \pm 8.0^{* * *} \\
(-6.4 \%)\end{array}$ \\
\hline & & Caucasian & $174.3 \pm 14$ & $\begin{array}{c}171.2 \pm 14.1 \\
(-1.8 \%)\end{array}$ & $\begin{array}{c}167.6 \pm 13.2^{* *} \\
(-3.9 \%)\end{array}$ & $\begin{array}{c}162.8 \pm 13.6^{* * *} \\
(-6.8 \%)\end{array}$ & $\begin{array}{c}160.9 \pm 13.4^{* * *} \\
(-7.8 \%)\end{array}$ \\
\hline & & Asian & $110.6 \pm 4.1$ & $\begin{array}{c}109.0 \pm 3.6^{*} \\
(-0.9 \%) \\
\end{array}$ & $\begin{array}{c}106.7 \pm 3.5 \\
(-2.7 \%) \\
\end{array}$ & $\begin{array}{c}104 \pm 3.5^{*} \\
(-5.1 \%)\end{array}$ & $\begin{array}{c}104.0 \pm 3.5^{*} \\
(-5.0 \%)\end{array}$ \\
\hline
\end{tabular}

Data are means of Sebum content $(\mu \mathrm{g} / \mathrm{cm} 2) \pm$ SEM. In brackets is reported the percentage variation vs. baseline. Intragroup (vs. baseline) statistical analysis is reported as follows: ${ }^{*} \mathrm{p}<0.05,{ }^{* *} \mathrm{p}<0.01$, and ${ }^{* * *} \mathrm{p}<0.001$. S Statistically different vs. placebo. 


\subsection{Subjective Self-Assessment of the Properties of the Product}

The subjective and qualitative evaluation of the efficacy of the product showed that according to study subjects, the use of the dietary supplement was beneficial for their skin. The results of the subject questionnaire are show $n$ in Table 5.

All effects were more positively assessed by the treatment group as compared to the placebo group, largely at the end of the study with incremental improvements occurring from Weeks 4 to 12 . Of note, statistically significant differences between groups were found at the end of the study in 9 of the 13 questions.

Regarding question 11 , since $50 \%$ of the enrolled panel clinically presented sensitive skin, the answers were assessed by subdividing the subjects in sensitive/not sensitive skin. As a result, 80\% of the subjects with sensitive skin perceived less discomfort relate to pollution-induced sensitivity only after 4 weeks. This difference was statistically significant compared with the placebo group both at week 4 and week 12.

Table 5: Results of self-assessment questions for the treatments and placebo at week 4 and 12.

\begin{tabular}{|c|c|c|c|c|}
\hline \multirow{2}{*}{ Questions } & \multicolumn{2}{|c|}{ Week 4} & \multicolumn{2}{|c|}{ Week 12} \\
\hline & Placebo & Treatment & Placebo & Treatment \\
\hline 1. My skin is protected from environmental pollution & $58 \%$ & $72 \%$ & $62 \%$ & $84 \% *$ \\
\hline 2. I perceive a protec tive sensation on my skin & $64 \%$ & $74 \%$ & $64 \%$ & $84 \%$ * \\
\hline 3. My complexion is more uniform & $62 \%$ & $74 \%$ & $68 \%$ & $84 \%$ \\
\hline 4. My skin is brighter & $62 \%$ & $74 \%$ & $68 \%$ & $76 \%$ \\
\hline 5. Wrinkles are less visible & $62 \%$ & $70 \%$ & $60 \%$ & $80 \% *$ \\
\hline 6. My skin is firmer & $58 \%$ & $70 \%$ & $68 \%$ & $82 \%$ \\
\hline 7. My skin complexion is healthier & $62 \%$ & $70 \%$ & $64 \%$ & $84 \% *$ \\
\hline 8. The colour of y our skin is lighter (whiter skin) & $52 \%$ & $60 \%$ & $52 \%$ & $74 \% *$ \\
\hline 9. I feel my skin more moisturized & $64 \%$ & $76 \%$ & $70 \%$ & $86 \% *$ \\
\hline 10. I feel my hair healthier and stronger & $54 \%$ & $68 \%$ & $62 \%$ & $80 \%$ \\
\hline \multirow{2}{*}{$\begin{array}{l}\text { 11. I feel less discomfort related to pollutants-sensitivity } \\
\text { Reply among people with sensitive skin }\end{array}$} & $58 \%$ & $70 \%$ & $58 \%$ & $82 \% *$ \\
\hline & $60 \%$ & $80 \% *$ & $60 \%$ & $84 \% *$ \\
\hline $\begin{array}{l}\text { 12. I notice an improvement of my skin imperfections } \\
\text { (dilated pores and/or pimples) }\end{array}$ & $58 \%$ & $66 \%$ & $68 \%$ & $82 \%$ \\
\hline 13. I would buy the product & $44 \%$ & $56 \%$ & $18 \%$ & $82 \% *$ \\
\hline
\end{tabular}

The results of question 1 to 12 are expressed with the percentage of subjects who selected Strongly Agree or Agree to the questions presented. Question 13 a re expressed as the percentage of subjects who would buy the product. Intergroup statistical analysis was performed between dietary supplement and placebo group (Caucasian+ Asian subjects) by means of Mann-Whitney statistical analysis. $\left.{ }^{*}\right)$ statistically significant $\mathrm{p}<0.05$

\section{Discussion}

The continual increase in air pollution worldwide is having a major negative impact on human health, including the skin. Although human skin shields against pollution, prolonged and repetitive exposure results in accelerated skin ageing, uneven skin pigmentation [8-11], inflammatory or allergic skin conditions such as atopic dermatitis and eczema, psoriasis, acne [12, 13], and even skin cancer [47]. As a result, preventive and reparative measures to maintain optimal skin health and reverse the negative effects of air pollution, both topically and orally, are being given increas ed attention. 
It is clear that air pollutants interfere with the normal functioning of the skin via oxidative damage to lipids, DNA and/or proteins [48-50]. In addition, the effect of air pollutants can be amplified in the presence of UV radiation [15]. Despite their different chemical nature and their mode of penetration into the skin, all air pollutants exert a harmful effect by increasing oxidative stress which counters the antioxidant defences of the affected tissue. There is a depletion of enzymatic (glutathione peroxidase, glutathione reductase, superoxide dismutase and catalase) and nonenzymatic (Vitamin E, Vitamin C and glutathione) antioxidant capacity [51,52]. Free radicals and ROS interact with thelipid-rich plasma membrane to initiate the lipid peroxidation reaction cascade. Lipid peroxidation may contribute to and amplify cellular damage resulting from the generation of oxidized products, some of which are chemically reactive and covalently modify critical macromolecules [53]. ROS also stimulate the release of pro-inflammatory mediators which results in the accumulation of neutrophils and other phagocy tic cells that further generate free radicals, thereby resulting in a vicious cycle. Thus, an anti-pollution ingredient's effectiveness will depend on its antioxidant capabilities to counterbalance harmful substances.

Many studies suggest that the combination of natural products in appropriated formulations represent a viable strategy for the treatment of skin conditions associated with inflammation and oxidative stress, both topically and orally $[19,54]$. Published reports have shown that individual extracts or main actives present in lemon verbena, olive leaf, Sophora japonica, and rosemary are effective antioxidants with the ability to counteract different environmentally induced skin damage. The antioxidant effects of olive polyphenols, such as oleuropein and hydroxytyrosol, have been extensively confirmed in the scientific literature [29,30]. Several components in olive oil have a direct antioxidant action on the skin, and it has been suggested to prevent against chronic UV-induced skin damage, including melanin production [55-57]. Hydroxytyrosol is also effective in reducing the harmful effect of light-mediated skin damage, including UVB [58], UVA [34] and blue light radiation [33]. Studies have shown that rosemary extract exhibits strong antioxidant and anti-inflammatory properties linked to its poly phenol content, particularly diterpenes (carnosic acid and carnosol) [18, $39,59,60]$. Rosemary plant and carnosic acid have been proven to possess anti-photoaging properties and prevent the expression of matrix metalloproteinases in skin fibroblasts and keratinocy tes [38, 61]. Carnosic acid has also been show $n$ to inhibit the oxidative stress levels on human fibroblasts exposed to UVA, urban dust and cigarette smoke [62]. In other studies, the antioxidant and main biological properties of lemon verbena are linked to the presence of glycosylated phenylpropanoid, mainly verbascoside $[63,64]$. Verbascoside, also known as acteoside, has been proven to have a wide range of activities, including antioxidant, anti-inflammatory, photoprotective, whitening and chelating actions [35-37, 65]. Finally, the role of Sophora japonica in Chinese Herbal Traditional Medicine is widely known, and numerous biological activities, such as antioxidant, anti-bacterial, anti-allergic, and anti-inflammatory, havebeen reported [31]. In addition, the photoprotective and anti-pollution effects of Sophora japonica havealso been studied $[32,66]$.

Skin exposure to PMs and other pollutants has been found to induce lipid peroxidation, as well as elevated levels of reactive aldehyde by-products like malondialdehyde (MDA) [4]. On the other hand, Total Antioxidant Capacity (TAC) is a recognized biomarker for measuring the antioxidant potential of body fluids that is also used to investigate oxidative stress in many pathological conditions [67]. Environmental pollutants can also affect TAC. Smoking, $\mathrm{O}_{3}$, heavy metals and toxic elements such as pesticides can decrease TAC, rendering subjects less resistant to oxidative and 
nitrosamine injuries and subsequent diseases [68-71]. The results of the present study showed that the oral intake of the product containing the four herbal extracts ingredient improved oxidative stress biomarkers by significantly reducing the MDA content on the skin stratum corneum and increasing the total antioxidant capacity of saliva (TAS) after 12 weeks and 4 weeks of product consumption, respectively. The increase of the TAS and the decrease of the skin LPOs indicate a positive effect of the product in improving the body's antioxidant capacity and interestingly it's targeting to the skin . The decrease of the oxidative stress in the skin could be a first step in decreasing the generation of free radicals by $\mathrm{PM}_{2} \mathrm{O}_{3}$ and other oxidants in the air pollution. On the other hand, the replenishment of antioxidants by dietary ingredients could be of primary importance in decreasing the ROSmediated depletion and both enzymatic and non-enzymatic antioxidant reserves in the skin with notable effects on Vitamin C and E levels [52,72].

The damaged barrier leads to higher transepidermal water loss (TEWL), resulting in poor skin hydration causing dry and sensitive skin. Strengthening the skin's barrier and improving hydration is also a promising antipollution strategy $[43,44]$. Pollution weakens the skin's natural barrier, resulting in higher and deeper penetration and accumulation of pollutants, which, in turn, affects the morphology and integrity of skin structure [73]. In this study, a positive effect of the product was also seen on skin parameters related to the skin`s barrier integrity where the improvement of skin moisturization correlated with TEWL decrease. A positive correlation was also seen in the itching sensation of people with sensitive skin as we showed in the subject self-assessment questionnaire.

Pollutant exposure has been linked with premature skin ageing. In the present study, an improvement of the skin's firmness and elasticity were observed. Additionally, the skin became smoother and the depth of the w rinkles was reduced in the crow feet area. These improvements were observed after only 2 w eeks of taking the dietary supplement.

Although the underlying mechanisms by which the active ingredient improves skin w rinkles, hydration, elasticity, and roughness were not investigated in this clinical trial, we suggest that Zeropollution supplement may have a positive effect on the extracellular matrix status through the antioxidative activities of the phenolic compounds present in the active formulation. PMs and other pollutants induce ROS and inflammatory mediators that produce the activation of nuclear transcription complex AP-1, through intracellular kinases signalling activation (MAP kinases, p38 and JNK), leading to metalloproteinases (MMPs) activation and decreased expression of collagen and other matrix proteins with the final consequence of reduced dermal matrix formation [74].

A positive correlation was also observed for the improvement of overall skin complexion. The daily plant-based nutraceutical consumption provided exceptional skin brightening benefits (5 times more than the placebo group) and significantly lightened the hyperpigmented areas on the cheekbone (2.5 times more than the placebo group). These improvements w ere statistically significant compared to the placebogroup after only 2 weeks of taking the dietary supplement.

In addition to the antioxidant effects of the polyphenolic blend, many of its beneficial properties may be mediated through the inhibition of the AhR receptor overexpression induced by pollutants as we show $n$ in a living human skin explants $[40,41]$. The aryl hydrocarbon receptor is a ligand-activated transcription factor found in various skin cells, including keratinocytes, fibroblasts, melanocytes, and Langerhans cells. Non-activated AhR is trapped in the cytosol but under the effect of various environmental aggressors (i.e., UV radiation, $\mathrm{O}_{3}$, tobacco smoke, and air pollutants, 
especially PAH-rich particulate matter) AhR translocates to the nucleus where it stimulates the expression of genes containing the xenobiotic response. Some of these genes control the expression of proteins involved in oxidative stress reactions, inflammation, immunosuppression, pigmentation, premature ageing, and cancer in the skin [75]. For instance, the AhR activation increases MMP-1 and MMP-3 expression, which in turn promotes collagen degradation and reduced collagen biosynthesis. As a consequence, there is premature skin aging and the formation of coarse wrinkles and loss of elasticity [16,76]. Moreover, the AhR activation also causes an increase in ty rosinase activity and total melanin content, which are related to pigment spots formation, and even skin cancer [77]. Furthermore, the connection betw een inflammatory skin diseases and AhR transcript levels has been described [78].

In this clinical trial, the benefits of the product were substantiated by a self-assessment questionnaire as the treatment product was highly rated by volunteers regarding its efficacy. Of note, $82 \%$ of participants in the treatment group w ould purchase the product. The importance of the user opinion, specially having a nutraceutical ingredient with cosmetic properties cannot be underestimated because it helps to comply with the product adherence.

The strengths of this study include the randomized, double-blind, placebo-controlled design and use of an equal distribution of women across a broad range of age groups, skin type, skin sensitivity. In addition, compared to other studies performed in this area, the study population size was relatively large and included both Asian and Caucasian subjects. Additional strengths include the control of external variables (e.g., sun or tanning bed exposure, dietary supplement use, etc.) that could interfere with the observed results, as well as utilization of standardized facial cleanser and moisturizer throughout the study. Despite these strengths, some limitations that are worth noting, for instance, the regulatory authorities have not yet established standardized methods for validating the antipollution efficacy of cosmetic or nutritional products on human skin. Furthermore, all the volunteers in the clinical trial were female, how ever, we believe that our results can be extended to the general population since the molecular, cellular, and tissue-specific events leading oxidation, inflammation, and skin ageing are shared among genders.

The main objective of this study was to evaluate the ability of the multi-herbal active ingredient to protect the skin of subjects living in a highly polluted environment, during the winter season, a time frame characterized by high air pollution (especially PM10 and PM2.5). During the study evaluation, high pollution days (exceeding the WHO guideline) represented $90 \%$ and $96 \%$ of the entire study period for PM 10 and PM 2.5, respectively. This supports the fact that we tested the skin protective effect of the dietary supplement under a suitable time frame to evaluate its antipollution effect. In conclusion, the results of the study indicate a positive effect of the dietary supplement in improving the skin conditions of both Asian and Caucasian females living in a polluted urban area (Milan, Italy). To our knowledge, this is the first clinical study set out to explore the efficacy of a nutraceutical ingredient to prevent the harmful effects of air pollutants on the skin.

\section{Patents}

The product evaluated in this investigation is patented (WO/2019/211501) and some of the results of this research are included.

Supplementary Materials: Figure S1: Environmentalconditions and air quality during the study period. 
Author Contributions: V.N., I.S. and N.C. participated in the study conceptualization; NC. a nd A.P designed the formulation; I.S., S.G. and E.S. participated in the data acquisition and analysis; V.Nand I.S interpre ted the data. V.N., I.S. and N.C. wrote and revie wed the manuscript. N.C. and A.P. assisted with project administration and funding acquisition. All authors have read and agreed to the published version of the manuscript.

Funding: This research was partially funded by IVACE (Instituto Valenciano de Competitividad Empre sarial) within the IVACE grant program for R\&D projects of SMEs (project code IMIDTA/2019/26).

Acknowledgements: The authors would like to thank Dr. Jonathan Jones for critically reading the manuscript and helpful comments.

Conflicts of Interest: N.C. and A.P. belong to Monteloe der SL.

\section{References}

1. WHO: Air pollution levels rising in many of the world's poorest cities. World Health Organisation Global Ambient Air Quality Database (update 2018). https://www.who.int/airpollution/data/cities/en/.

2. Huang, N.; Mi, T.; Xu, S.; Dadd, T.; Ye, X.; Chen, G.; Du, Y.; Santhanam, U. Traffic-De rived Air Pollution Compromises Skin Barrier Function and Stratum Corneum Redox Status: A Population Study. J Cosmet Dermatol, 2020, 19 (7), 1751-1759. https://doi.org/10.1111/jocd.13194.

3. Jin, S.-P.; Li, Z.; Choi, E. K.; Lee, S.; Kim, Y. K.; Seo, E. Y.; Chung, J. H.; Cho, S. Urban Particulate Matter in Air Pollution Penetrates into the Barrier-Disrupted Skin and Produces ROS-Dependent Cutaneous Inflamma tory Response in Vivo. J. Dermatol. Sci., 2018. https://doi.org/10.1016/j.jdermsci.2018.04.015.

4. Dijkhoff, I. M.; Drasler, B.; Karakocak, B. B.; Petri-Fink, A.; Valacchi, G.; Eeman, M.; Rothen-Rutishauser, B. Impact of Airborne Particulate Matter on Skin: A Systematic Review from Epidemiology to in Vitro Studies. Part Fibre Toxicol, 2020, 17 (1), 35. https://doi.org/10.1186/s12989-020-00366-y.

5. Krutmann, J.; Bouloc, A.; Sore, G.; Bernard, B. A.; Passeron, T. The Skin Aging Exposome. J. Dermatol. Sci, 2017, 85 (3), 152-161. https://doi.org/10.1016/j.jdermsci.2016.09.015.

6. Hüls, A.; Sugiri, D.; Fuks, K.; Krutmann, J.; Schikowski, T. Lentigine Formation in Caucasian WomenInteraction between Particulate Matter and Solar UVR. J. Invest. Dermatol., 2019, 139 (4), 974-976. https://doi.org/10.1016/j.jid.2018.09.034.

7. Mancebo, S. E.; Wang, S. Q. Recognizing the Impact of Ambient Air Pollution on Skin Health. J Eur Acad Dermatol Venereol, 2015, 29 (12), 2326-2332. https://doi.org/10.1111/jdv.13250.

8. Krämer, U.; Sugiri, D.; Ranft, U.; Krutmann, J.; von Berg, A.; Berdel, D.; Behrendt, H.; Kuhlbusch, T.; Hochadel, M.; Wichmann, H.-E.; et al. Eczema, Respiratory Allergies, and Traffic-Related Air Pollution in Birth Cohorts from Small-Town Areas. J. Dermatol. Sci., 2009, 56 (2), 99-105. https://doi.org/10.1016/j.jdermsci.2009.07.014.

9. Larrieu, S.; Lefranc, A.; Gault, G.; Chatignoux, E.; Couvy, F.; Jouves, B.; Filleul, L. Are the Short-Term Effects of Air Pollution Restricted to Cardiorespiratory Diseases? Am. J. Epidemiol., 2009, 169 (10), 1201-1208. https://doi.org/10.1093/aje/kwp032.

10. Lu, X.; Zhang, X.; Li, L. Y.; Chen, H. Assessment of Metals Pollution and Health Risk in Dust from Nursery Schools in Xi'an, China. Environ. Res., 2014, 128, 27-34. https://doi.org/10.1016/j.envres.2013.11.007.

11. Vierkötter, A.; Schikowski, T.; Ranft, U.; Sugiri, D.; Matsui, M.; Krämer, U.; Krutmann, J. Airborne Particle Exposure and Extrinsic Skin Aging. J. Invest. Dermatol., 2010, 130 (12), 2719-2726. https://doi.org/10.1038/jid.2010.204.

12. Kim, J.; Kim, E.-H.; Oh, I.; Jung, K.; Han, Y.; Cheong, H.-K.; Ahn, K. Symptoms of Atopic Dermatitis Are Influenced by Outdoor Air Pollution. J. Allergy Clin. Immunol., 2013, 132 (2), 495-498.e1. https://doi.org/10.1016/j.jaci.2013.04.019.

13. Xu, F.; Yan, S.; Wu, M.; Li, F.; Xu, X.; Song, W.;Zhao, J.; Xu, J.; Kan, H. Ambient Ozone Pollution as a Risk Factor for Skin Disorders. Br. J. Dermatol., 2011, 165 (1), 224-225. https://doi.org/10.1111/j.13652133.2011.10349.x. 
14. Juliano, C.; Magrini, G. A. Cosmetic Functional Ingredients from Botanical Sources for Anti-Pollution Skincare Products. Cosmetics, 2018, 5 (1), 19. https://doi.org/10.3390/cosmetics5010019.

15. Marrot, L. Pollution and Sun Exposure: A Deleterious Synergy. Mechanisms and Opportunities for Skin Protection. Curr. Med. Chem., 2018, 25 (40), 5469-5486. https://doi.org/10.2174/0929867324666170918123907.

16. Parrado, C.; Mercado-Saenz, S.; Perez-Davo, A.; Gilaberte, Y.; Gonzalez, S.; Juarranz, A. Environmental Stressors on Skin Aging. Mechanistic Insights. Front Pharmacol, 2019, 10, 759. https://doi.org/10.3389/fphar.2019.00759.

17. Araviiskaia, E.; Berardesca, E.; Bieber, T.; Gontijo, G.; Sanchez Viera, M.; Marrot, L.; Chuberre, B.; Dreno, B. The Impact of Airborne Pollution on Skin. J Eur Acad De rmatol Venereol, 2019, 33 (8), 1496-1505. https://doi.org/10.1111/jdv.15583.

18. Nobile, V.; Michelotti, A.; Cestone, E.; Caturla, N.; Castillo, J.; Benavente-García, O.; Pérez-Sánchez, A.; Micol, V.Skin Photoprotective and Antiageing Effects of a Combination of Rosemary (Rosmarinus Officinalis) and Grapefruit (Citrus Paradisi) Polyphenols. Food Nutr Res, 2016, 60, 31871. https://doi.org/10.3402/fnr.v60.31871.

19. Pérez-Sánchez, A.; Barrajón-Catalán, E.; Herranz-López, M.; Micol, V. Nutraceuticals for Skin Care: A Comprehensive Review of Human Clinical Studies. Nutrients, 2018, $10 \quad$ (4). https://doi.org/10.3390/nu10040403.

20. Parrado, C.; Philips, N.; Gilaberte, Y.; Juarranz, A.; González, S. OralPhotoprotection: Effective Agents and PotentialCandidates. Frontiers in Medicine, 2018, 5, 188. https://doi.org/10.3389/fmed.2018.00188.

21. Romieu, I.; Castro-Giner, F.; Kunzli, N.; Sunyer, J. Air Pollution, Oxidative Stress and Dietary Supplementation: A Review. Eur. Respir. J., 2008, 31 (1), 179-197. https://doi.org/10.1183/09031936.00128106.

22. Whyand, T.; Hurst, J. R.; Beckles, M.; Caplin, M. E. Pollution and Respiratory Disease: Can Diet or Supplements Help? A Review. Respir. Res., 2018, 19 (1), 79. https://doi.org/10.1186/s12931-018-0785-0.

23. Nguyen, L. T. H.; Nguyen, U. T.; Kim, Y.-H.; Shin, H.-M.; Yang, I.-J. Astragali Radix and Its Compound Formononetin Ameliorate Diesel Particulate Matter-Induced Skin Barrier Disruption by Regulation of Keratinocyte Proliferation and Apoptosis. J Ethnopharmacol, 2019, 228, $132-141$. https://doi.org/10.1016/j.jep.2018.09.025.

24. Milani, M.; Hashtroody, B.; Piacentini, M.; Celleno, L. Skin Protective Effects of an Antipollution, Antioxidant Serum Containing Deschampsia Antartica Extract, Ferulic Acid and Vitamin C: A Controlled Single-Blind, Pros pective Trial in Women Living in Urbanized, High Air Pollution Area. Clin Cosmet Investig Dermatol, 2019, 12, 393-399. https://doi.org/10.2147/CCID.S204905.

25. Seok, J. K.; Lee, J.-W.; Kim, Y. M.; Boo, Y. C. Punicalagin and (-)-Epigallocatechin-3-Gallate Rescue Cell Viability and Attenuate Inflammatory Responses of Human EpidermalKeratinocytes Exposed to Airborne Particulate Matter PM10. Skin Pharmacol Physiol, 2018, 31 (3), 134-143. https://doi.org/10.1159/000487400.

26. Zhen, A. X.; Hyun, Y. J.; Piao, M. J.; Fernando, P. D. S. M.; Kang, K. A.; Ahn, M. J.; Yi, J. M.; Kang, H. K.; Koh, Y. S.; Lee, N. H.; et al. Eckol Inhibits Particulate Matter 2.5-Induced Skin Keratinocyte Damage via MAPK Signaling Pathway. Mar Drugs, 2019, 17 (8). https://doi.org/10.3390/md17080444.

27. Choi, M. A.; Seok, J. K.; Boo, Y. C. P-354 - Resveratrol and Resveratryl Triacetate Attenuate Inflammatory Responses and Reactive Oxygen Species in Human Epidermal Keratinocytes Exposed to Particulate Matter PM10. Free Radical Biology and Medicine, 2018, 120, S152. https://doi.org/10.1016/j.freeradbiomed.2018.04.501.

28. Pambianchi, E.; Ferrara, F.; Pecorelli, A.; Woodby, B.; Grace, M.; Therrien, J.-P.; Lila, M. A.; Valacchi, G. Blueberry Extracts as a Novel Approach to Prevent Ozone-Induced Cutaneous Inflammasome Activation. Oxid Med Cell Longev, 2020, 2020. https://doi.org/10.1155/2020/9571490.

29. Bulotta, S.; Celano, M.; Lepore, S. M.; Montalcini, T.; Pujia, A.; Russo, D. Beneficial Effects of the Olive Oil Phenolic Components Oleuropein and Hydroxytyrosol: Focus on Protection against Cardiovascular and Metabolic Diseases. J Transl Med, 2014, 12, 219. https://doi.org/10.1186/s12967-014-0219-9. 
30. Serreli, G.; Incani, A.; Atzeri, A.; Angioni, A.; Campus, M.; Cauli, E.; Zurru, R.; Deiana, M. Antioxidant Effect of Natural Table Olives Phenolic Extract Against Oxidative Stress and Membrane Damage in EnterocyteLike Cells. J. Food Sci., 2017, 82 (2), 380-385. https://doi.org/10.1111/1750-3841.13613.

31. He, X.; Bai, Y.; Zhao, Z.; Wang, X.; Fang, J.; Huang, L.; Zeng, M.; Zhang, Q.; Zhang, Y.; Zheng, X. Local and TraditionalUses, Phytochemistry, and Pharmacology of Sophora Japonica L.: A Review. J Ethnopharma col, 2016, 187, 160-182. https://doi.org/10.1016/j.jep.2016.04.014.

32. Li, L.; Huang, T.; Lan, C.; Ding, H.; Yan, C.; Dou, Y. Protective Effect of Polysaccharide from Sophora Japonica L. Flower Buds against UVB Radiation in a Human Keratinocyte Cell Line (HaCaT Cells). J. Photochem. Photobiol. B, Biol., 2019, 191, 135-142. https://doi.org/10.1016/j.jphotobiol.2018.12.001.

33. Avola, R.; Graziano, A. C. E.; Pannuzzo, G.; Bonina, F.; Cardile, V. Hydroxytyrosol from Olive Fruits Prevents Blue-Light-Induced Damage in Human Keratinocytes and Fibroblasts. J. Cell. Physiol., 2019, 234 (6), 9065 9076. https://doi.org/10.1002/jcp.27584.

34. Jeon, S.; Choi, M. Anti-Inflammatory and Anti-Aging Effects of Hydroxytyrosol on Human Dermal Fibroblasts (HDFs). Biome dicalDermatology, 2018, 2 (1), 21. https://doi.org/10.1186/s41702-018-0031-x.

35. Young-Ok, S.; Seung-Ah, L.; Seung-Ah, L.; So-Soon, K.; Yong-Suk, J.; Jae-Chul, C.; Jeong-Chae, L. Acte oside Inhibits Melanogenesis in B16F10 Cells through ERK Activation and Tyrosinase Down-Regulation. Journal of Pharmacy and Pharmacology, 2011, 63 (10), 1309-1319.

36. Vertuani, S.; Beghelli, E.; Scalambra, E.; Malisardi, G.; Copetti, S.; Toso, R. D.; Baldisserotto, A.; Manfre dini, S. Activity and Stability Studies of Verbascoside, a Novel Antioxidant, in Dermo-Cosmetic and Pharmaceutical Topical Formulations. Molecules, 2011, $16 \quad$ (8), 7068-7080. https://doi.org/10.3390/molecules16087068.

37. Espinosa-González, A. M.; García-Bores, A. M.; Benítez-Flores, J. del C.; Sandoval-Pérez, C. E.; GonzálezValle, M. del R.; Céspedes, C. L.; Avila-Acevedo, J. G. Photoprotective effect of verbascoside from Buddleja cordata in SKH-1 mice exposed to acute and chronic UV-B radia tion. Bole tín La tinoa me ricano y delCaribe de Plantas Medicinales y Aromáticas, 2016, 15 (5), 288-300.

38. Park, M.; Han, J.; Lee, C. S.; Soo, B. H.; Lim, K.-M.; Ha, H. Carnosic Acid, a Phenolic Diterpene from Rosemary, Prevents UV-Induced Expression of Matrix Metalloproteinases in Human Skin Fibroblasts and Keratinocytes. Exp. Dermatol., 2013, 22 (5), 336-341. https://doi.org/10.1111/exd.12138.

39. Habtemariam, S. The The rapeutic Potential of Rosemary (Rosmarinus Officinalis) Diterpenes for Alzheimer's Dise a se. Evid Based Complement AlternatMed, 2016, 2016, 2680409. https://doi.org/10.1155/2016/2680409.

40. Caturla, N.; Peral, A.; Radionov, N.; Peno-Mazzarino, L. Pre-Clinical Evaluation of the Antioxidative and Anti-Infla mma tory Effects of an Oral Four-Component Plant-Ba sed Product against UV-B and Standardised Urban Pollution. Manuscript Submitted for Publication. 2020.

41. Caturla Cernuda, N.; Peral Clement, A. Composición De Extractos Vegetales Con Flavonoides Para Paliar Los Múltiples Efectos De La Contaminación Del Aire Sobre La Piel. WO/2019/211501, November 7, 2019.

42. Anenberg, S. A Global Snapshot of the Air Pollution-Related Health Impacts of Transportation Sector Emissions in 2010 and 2015. 55.

43. Mistry, N. Guidelines for Formulating Anti-Pollution Products. Cosmetics, 2017, 4 (4), 57. https://doi.org/10.3390/cosmetics4040057.

44. Rembiesa, J.; Ruzgas, T.; Engblom, J.; Holefors, A. The Impact of Pollution on Skin and Proper Efficacy Testing for Anti-Pollution Claims. Cosmetics, 2018, 5 (1), 4. https://doi.org/10.3390/cosmetics5010004.

45. Erdelmeier, I.; Gérard-Monnier, D.; Yadan, J. C.; Chaudiè re, J. Reactions of N-Methyl-2-Phenylindole with Malondialdehyde and 4-Hydroxyalkenals. Mechanistic Aspects of the Colorimetric Assay of Lipid Peroxidation. Chem. Res. Toxicol., 1998, 11 (10), 1184-1194. https://doi.org/10.1021/tx970180z.

46. Benzie, I. F.; Strain, J. J. The Ferric Reducing Ability of Plasma (FRAP) as a Measure of "Antioxidant Power": The FRAP Assay. Anal. Biochem., 1996, 239 (1), 70-76. https://doi.org/10.1006/abio.1996.0292. 
47. Baudouin, C.; Charveron, M.; Tarroux, R.; Gall, Y. Environmental Pollutants and Skin Cancer. Cell Biol. Toxicol., 2002, 18 (5), 341-348. https://doi.org/10.1023/a:1019540316060.

48. Menzel, D. B. The Toxicity of Air Pollution in Experimental Animals and Humans: The Role of Oxidative Stress. Toxicol. Lett., 1994, 72 (1-3), 269-277. https://doi.org/10.1016/0378-4274(94)90038-8.

49. Valko, M.; Leibfritz, D.; Moncol, J.; Cronin, M. T. D.; Mazur, M.; Telser, J. Free Radicals and Antioxidants in Normal Physiological Functions and Human Disease. Int. J. Biochem. Cell Biol., 2007, 39 (1), 44-84. https://doi.org/10.1016/j.biocel.2006.07.001.

50. Kampa, M.; Castanas, E. Human Health Effects of Air Pollution. Environ. Pollut., 2008, 151 (2), $362-367$. https://doi.org/10.1016/j.envpol.2007.06.012.

51. Valacchi, G.; Sticozzi, C.; Pecorelli, A.; Cervellati, F.; Cervellati, C.; Maioli, E. Cutaneous Responses to Environmental Stressors. Ann. N. Y. Acad. Sci., 2012, 1271, 75-81. https://doi.org/10.1111/j.17496632.2012.06724.x.

52. Thiele, J. J.; Traber, M. G.; Polefka, T. G.; Cross, C. E.; Packer, L. Ozone-Exposure Depletes Vitamin E and Induces Lipid Peroxidation in Murine Stratum Corneum. J. Invest. Dermatol., 1997, 108 (5), 753-757. https://doi.org/10.1111/1523-1747.ep12292144.

53. Uchida, K. 4-Hydroxy-2-Nonenal: A Product and Me dia tor of Oxidative Stress. Prog. Lipid Res., 2003, 42 (4), 318-343. https://doi.org/10.1016/s0163-7827(03)00014-6.

54. Dunaway, S.; Odin, R.; Zhou, L.; Ji, L.; Zhang, Y.; Kadekaro, A. L. Natural Antioxidants: Multiple Mechanisms to Protect Skin From Solar Radiation. Front Pharmacol, 2018, 9. https://doi.org/10.3389/fphar.2018.00392.

55. Ancora, C.; Roma, C.; Vettor, M. Evalua tion of Cosmetic Effica cy of Oleoeuropein.; Rome. Italy, 2004.

56. Kimura, Y.; Sumiyoshi, M. Olive Leaf Extract and Its Main Component Oleuropein Prevent Chronic Ultra violet B Radiation-Induced Skin Damage and Carcinogenesis in Hairless Mice. J. Nutr., 2009, 139 (11), 2079-2086. https://doi.org/10.3945/jn.109.104992.

57. Ha, J. Y.; Choi, H. K.; Oh, M. J.; Choi, H.-Y.; Park, C. S.; Shin, H.-S. Photo-protective and Anti-melanogenic Effect from Phenolic Compound of Olive Leaf (Olea europaea L. var. Kalamata) Extracts on the Immortalized Human Keratinocytes and B16F1 Melanoma Cells https://www.dbpia.co.kr/Journal/articleDetail?nodeId=NODE01711837 (accessed Sep 14, 2020).

58. Guo, W.; An, Y.; Jiang, L.; Geng, C.; Zhong, L. The Protective Effects of Hydroxytyrosol against UVB-Induced DNA Damage in HaCa T Cells. PhytotherRes, 2010, 24 (3), 352-359. https://doi.org/10.1002/ptr.2943.

59. Bakirel, T.; Bakirel, U.; Keleş, O. U.; Ulgen, S. G.; Yardibi, H. In Vivo Assessment of Antidiabetic and Antioxidant Activities of Rosemary (Rosmarinus Officinalis) in Alloxan-Diabetic Rabbits. J Ethnopharmacol, 2008, 116 (1), 64-73. https://doi.org/10.1016/j.jep.2007.10.039.

60. Birtić, S.; Dussort, P.; Pierre, F.-X.; Bily, A. C.; Roller, M. Carnosic Acid. Phytochemistry, 2015, 115, 9-19. https://doi.org/10.1016/j.phytochem.2014.12.026.

61. Offord, E. A.; Gautier, J.-C.; Avanti, O.; Scaletta, C.; Runge, F.; Krämer, K.; Applegate, L. A. Photoprotective Potential of Lycopene, Beta-Carotene, Vitamin E, Vitamin C and Carnosic Acid in UVA-Irradiated Human Skin Fibroblasts. Free Ra dic. Biol. Med., 2002, 32 (12), 1293-1303. https://doi.org/10.1016/s0891-5849(02)008316.

62. Hubaux, R.; Weisgerber, F.; Salmon, M. In Vitro Assays to Study the Effects of Air Pollutants on Skin: Exposure to Urban Dust and Cigarette Smoke Extract.; Montreux (Switzerland)., 2015.

63. Pérez-Sánchez, A.; Barrajón-Catalán, E.; Herranz-López, M.; Castillo, J.; Micol, V. Lemon Balm Extract (Melissa Officinalis, L.) Promotes Melanogenesis and Prevents UVB-Induced Oxidative Stress and DNA Damage in a Skin Cell Model. J Dermatol Sci, 2016, 84 (2), 169-177. https://doi.org/10.1016/j.jdermsci.2016.08.004.

64. Sánchez-Marzo, N.; Lozano-Sánchez, J.; Cádiz-Gurrea, M. de la L.; Herranz-López, M.; Micol, V.; SeguraCarretero, A. Relationships Between Chemical Structure and Antioxidant Activity of Isolated 
Phytocompounds from Lemon Verbena. Antioxidants (Basel), 2019, $8 \quad$ (8). https://doi.org/10.3390/antiox8080324.

65. Korkina, L. G.; Mikhal'chik, E.; Suprun, M. V.; Pastore, S.; DalToso, R. Molecular Mechanisms Underlying Wound Healing and Anti-Inflammatory Properties of Naturally Occurring Biotechnologically Produced Phenylpropanoid Glycosides. Cell. Mol. Biol. (Noisy-le-grand), 2007, 53 (5), 84-91.

66. Kim, M.; Son, D.; Shin, S.; Park, D.; Byun, S.; Jung, E. Protective Effects of Camellia Ja ponica Flower Extract against Urban Air Pollutants. BMC Complementary and Alternative Medicine, 2019. https://doi.org/10.1186/s12906-018-2405-4.

67. Peluso, I.; Raguzzini, A. Salivary and Urinary Total Antioxidant Capacity as Biomarkers of Oxidative Stress in Humans. Patholog Res Int, 2016, 2016, 5480267-5480267. https://doi.org/10.1155/2016/5480267.

68. Bocci, V.; Valacchi, G.; Corradeschi, F.; Fanetti, G. Studies on the Biological Effects of Ozone: 8. Effects on the Total Antioxidant Status and on Interleukin-8 Production. Mediators Inflamm, 1998, 7 (5), 313-317.

69. Bucalen, C. F. Effects of Xenobiotics on Total Antioxidant Ca pacity. Interdisciplinary Toxicology, 2012, 5 (3), 117-122. https://doi.org/10.2478/v10102-012-0019-0.

70. Goraca, A.; Skibska, B. Plasma Antioxidant Status in Healthy Smoking and Non-Smoking Men. Bratis1 Lek Listy, 2005, 106 (10), 301-306.

71. Baliga, M. S.; Shivashankara, A. R.; Rao, S.; Rai, M. P.; Mane, P. P.; Tonse, R.; Vashitha, A. Saliva as an Important Body Fluid in the Detection of Oxidative Stress in Community Based Studies: Preliminary Study with Police Personnel's Exposed to Automobile Exhaust. Int. J. Appl. Res., 2017, 3 (6), 372-376.

72. Park, S.-Y.; Byun, E. J.; Lee, J. D.; Kim, S.; Kim, H. S. Air Pollution, Autophagy, and Skin Aging: Impact of Particulate Matter (PM10) on Human Dermal Fibroblasts. Int J Mol Sci, 2018, 19 (9). https://doi.org/10.3390/ijms19092727.

73. Pan, T.-L.; Wang, P.-W.; Aljuffali, I. A.; Huang, C.-T.; Lee, C.-W.; Fang, J.-Y. The Impact of Urban Particulate Pollution on Skin Barrier Function and the Subsequent Drug Absorption. J. Dermatol. Sci., 2015, 78 (1), 5160. https://doi.org/10.1016/j.jdermsci.2015.01.011.

74. Fisher, G. J.; Kang, S.; Varani, J.; Bata-Csorgo, Z.; W an, Y.; Datta, S.; Voorhees, J. J. Mechanisms of Photoaging and Chronological Skin Aging. Arch Dermatol, 2002, 138 (11), 1462-1470. https://doi.org/10.1001/archderm.138.11.1462.

75. Furue, M.; Takahara, M.; Nakahara, T.; Uchi, H. Role of AhR/ARNT System in Skin Homeostasis. Arch DermatolRes, 2014, 306 (9), 769-779. https://doi.org/10.1007/s00403-014-1481-7.

76. Kung, T.; Murphy, K. A.; White, L. A. The Aryl Hydrocarbon Receptor (AhR) Pathway as a Regulatory Pathway for Cell Adhesion and Matrix Metabolism. Biochem. Pharmacol., 2009, 77 (4), 536-546. https://doi.org/10.1016/j.bcp.2008.09.031.

77. Luecke, S.; Backlund, M.; Jux, B.; Esser, C.; Krutmann, J.; Rannug, A. The ArylHydrocarbon Receptor (AHR), a Novel Regulator of Human Melanogenesis. Pigment Cell Melanoma Res, 2010, 23 (6), 828-833. https://doi.org/10.1111/j.1755-148X.2010.00762.x.

78. Kim, H. O.; Kim, J. H.; Chung, B. Y.; Choi, M. G.; Park, C. W. Increased Expression of the ArylHydrocarbon Receptor in Patients with Chronic Inflammatory Skin Diseases. Exp. Dermatol., 2014, 23 (4), $278-281$. https://doi.org/10.1111/exd.12350. 